\title{
RFID in the Warehouse: A Literature Analysis (1995-2010) of its Applications, Benefits, Challenges and Future Trends
}

\begin{abstract}
Radio frequency identification (RFID) has been identified as a crucial technology for the modern $21^{\text {st }}$ century knowledge-based economy. Many businesses started realising RFID to be able to improve their operational efficiency, achieve additional cost savings, and generate opportunities for higher revenues. To investigate how RFID technology has brought an impact to warehousing, a comprehensive analysis of research findings available through leading scientific article databases was conducted. Articles from years 1995 to 2010 were reviewed and analysed according to warehouse operations, RFID application domains, and benefits achieved. This paper presents four discussion topics covering RFID innovation, including its applications, perceived benefits, obstacles to its adoption and future trends. This is aimed at elucidating the current state of RFID in the warehouse and giving insights for the academics to establish new research scope and for the practitioners to evaluate their assessment of adopting RFID in the warehouse.
\end{abstract}

Keywords: RFID, warehouse operations

\section{Introduction}

Radio frequency identification (RFID), one of the wireless automatic identification and data capture (AIDC) technologies (Wamba, Lefebvre et al. 2008), is rapidly emerging and has attracted significant attention in the fields of supply chain and manufacturing, and more recently, in various service sectors. As the name implies, RFID transmits information through radio waves between RFID tags (or transponders) and readers (interrogators) (Hunt et al., 2007). The collected information is passed on to RFID middleware for processing, for use in business applications. Each tag consists of unique identification information about the item to which it is attached to, e.g. item ID, date of production, shipping detail, expiry date, etc. depending on the intended uses. As a means of collecting, transmitting and utilising data, RFID offers vast advantages over other AIDC technologies such as barcodes (Holmes, 2005; Brown et al., 2007). The benefits of RFID are well-perceived by the industries, such as retail, logistics, manufacturing, the military, healthcare, pharmaceuticals and the service sector (Oztaysi et al., 2009; Ngai et al., 2008). A substantial range of RFID applications have been implemented; each industry has a unique interest in the technological benefits for their business. These benefits include unique identification of each tagged item and status monitoring, improved stock visibility and traceability at any stage in the supply chain, increased data accuracy and sharing, automated inventory counts, automated receiving and scanning, reduced shrinkages, and so on (Ngai et al., 2008; Brown et al., 2007; Anonymous, 2005; Holmes, 2005; Luckett, 2004).

As pioneers of RFID adoption, Wal-Mart and the US Department of Defence had carried out trials on RFID application in their supply chain and have reported promising outcomes.

Mandates were issued in phases for their suppliers to apply RFID tags on their shipments (O'Connor, 2008). Other early adopters include Procter \& Gamble, Gap, Tesco UK, and Marks \& Spencer UK (Collins, 2006a; Collins, 2006b; Bacheldor, 2006; Collins, 2004b). More recently, large-scale RFID projects have been implemented. DHL has tagged $1.3 \mathrm{~m}$ pallets for its delivery operations to all 89 Metro Cash \& Carry in France (Wessel, 2008), and Sam's Club (wholesales retail stores owned by Wal-Mart) has issued mandates for all their 
suppliers to apply RFID tags in stages (Burnell, 2009). There is evidence showing an increase of pilot trials and implementations over recent years (Roberti, 2006).

Due to its well-perceived capability and popularity in the business world, RFID has also gained a rapid growth of interest in the academic community across different disciplines. In order to ascertain the extend of RFID coverage in logistics literature, a preliminary bibliographic search was conducted using the ISI Web of Knowledge database. The ISI Web of Knowledge database is considered as a primary source for citation studies (Roth, 2005; Meho and Yang, 2007). Results of the query are illustrated in Figure 1, which shows the exponential growth of RFID publications from 1995 to 2010. The growing trend coincides with the forecast put forward by Ngai et al. (2008) and Chao et al. (2007). It can be noted in Figure 1 that, since their review on RFID literature up to 2005, the number of publications from 2005 to 2010 has proliferated, indicating a need to review this new literature.

Furthermore, as Figure 1 shows, the increasing number of RFID publications in the domains of transport, logistics and supply chain follows the growing trend of overall RFID research. Conversely, the particular interest in RFID in warehousing is rather stagnant and relatively small in comparison to other research domains. Warehousing is a critical supply chain function and such outlook (in Figure 1) suggests a greater demand to review this underfocused domain comprehensively. This is corroborated by Curtin et al. (2007) stated that amongst many domains in RFID research, warehousing comes as one of the key domains to greatly benefit from RFID adoption. Moreover, in the RFID literature warehouse application is mainly discussed as a subset. The relatively few publications focusing solely on RFID application in the warehouse include the use of RFID case-based reasoning for managing different warehouse operations (Poon et al., 2009; Chow et al., 2006), investment in improving inventory accuracy (Uckun et al., 2008), RFID adoption issues and implementation challenges in warehouses (Bahr and Lim, 2009), and an empirical study of RFID in the warehouse industry evaluating its costs and benefits (Vijayaraman and Osyk, 2006).

\section{[Insert Figure 1]}

This review of RFID research on warehousing aims to identify the gaps that have not been explored in previous works, in particular, with general or supply chain management scope. In other words, the reader can learn what benefits and applications of RFID in warehouses are strongly linked to identification and what associated benefits of RFID are seldom examined in the warehousing literature. Also, the current status of RFID solutions for warehousing is evaluated against previous recommendations. Moreover, potential RFID obstacles and future trends are examined from the warehousing perspective.

The above justifies the contribution of this paper to comprehensively review the academic literature on RFID in warehouses, considering its application and influence on warehouse operations. The research questions addressed in this work are: What is the state of RFID application in warehousing as presented in academic literature and what are the perceived benefits? Are the RFID benefits interlinked and could this help academics and practitioners to build a stronger case for the technology adoption? In order to answer these questions following objectives were set:

- To develop a framework classifying RFID literature, focusing on its warehousing subsets

- To review and analyse the literature, within the classification framework, how RFID has applied and added values in the warehouse 
- To examine the benefits of RFID in warehouse operations and rank them according to their perceived gains

- To study the future trends to provide insights for academics to establish new research domains and for practitioners to examine associated benefits to prove for a business case

This paper is organised as follows: Section 2 describes the methodology used in analysing the academic literature and four discussion topics have been identified. Section 3 discusses topic one, which is the framework to analyse the literature based on RFID application domains. It is then followed by Section 4 (topic two) using a benefits matrix to analyse the correlation between the benefits and warehouse operations and application domains for all the articles studied, so as to identify the popular and under-focused (but potentially value-added) benefits which could draw the attention of researchers and practitioners. Obstacles to RFID adoption in the warehouse (topic three) are discussed in Section 5 and the future trends of using RFID (topic four) are analysed in Section 6. Finally, concluding remarks will be given in Section 7.

\section{Methodology}

Up to 2010, there are two major literature reviews analysing the state of research on RFID technology: Ngai, et al. (2008) and Chao et al. (2007). They presented the scientific literature from 1991 to 2005 and 1995 to 2005 respectively. By means of bibliometric analysis, Chao et al. (2007) documented the number of publications per year, type, country and language and divided the RFID literature into technological innovation, organisational adoption and time of new challenge and diffusion. On the contrary, the literature review by Ngai, et al. (2008) is based on content-oriented classification and divided the literature into categories such as RFID applications, policies and security. The authors also provided a discursive analysis on the future research directions.

As discussed in previous section, there is a demand to conduct a comprehensive literature review of the current state of research related to RFID in warehouse operations, and an analysis to explore the future trends of RFID in warehousing in order to identify the new research directions and value-added applications for the academics and practitioners. In contrast to the general RFID literature reviews by Chao et al. (2007) and Ngai et al. (2008) this paper analyses the literature that pertains to the applications of RFID technology specifically in warehouse operations.

\subsection{Timeline of research literature}

This study explores the literature in consecutive years from 1995 to 2010. The choice of 1995 as a start of literature search follows the reasoning from Ngai et al. (2008) and is also justified by the results of bibliographical query as shown in Figure 1.

\subsection{Literature search}

The academic literature reviewed in this study was obtained from the leading databases of scholarly articles in order to review the field as comprehensively as possible. The scholar databases used in this study are:

1. ABI/Inform Complete

2. ACM Digital Library

3. EBSCO Business Source Complete

4. SCOPUS

5. Emerald

6. IEEE Xplore 

7. Science Direct
8. Springer Link
9. Taylor \& Francis

\subsection{Database query}

Despite the differences in performing literature search between the databases, in each case the following generic query was used: «(Title OR Abstract) CONTAINS ("radio frequency identification" OR rfid) AND (Title OR Abstract) CONTAINS (warehouse NOT "data warehouse") AND (Timespan)=1995-2010 AND (Article Type)=(Peer Reviewed)». It was necessary to exclude the phrase "data warehouse" as it does not refer to the warehouse in the supply chain. The search query resulted in 403 articles. Articles with duplicate entries due to database overlap, news articles from trade magazines and articles in languages other than English were discarded. The process of categorising and analysing the remaining 253 articles was modelled after practice outlined by Ngai et al. (2008), whereby two authors autonomously analysed the articles and discrepancies between authors' judgement were reconciled by discussion, with the input and agreement from the third author, until a unanimous decision was made whether to include article in the set. As a result, an additional of 195 articles was rejected because they were matching the query but did not focus on RFID research work in the warehouse (e.g. they only mentioned warehouse as an example for RFID application but did not actually conduct research in the domain). This leaves 58 articles to be analysed in this paper.

\subsection{Limitations}

This study is subject to a number of limitations. First of all, despite using 9 leading scholarly databases, there is a possibility of some scientific articles not being covered as they are not indexed in any of them. The second limitation is related to the characteristics of dynamic nature of online publication databases. As the articles become available from the publishers, some of them might have been added at a later stage and backdated. Therefore, the authors of this paper recognise that some articles may have not been included as they were not available on the databases at the time of writing. The last limitation is that this study is only focused on articles published in English language. Despite these limitations, it is believed that this study has achieved reliable comprehensiveness and can benefit academics and practitioners in establishing new research directions and evaluating their assessment of applying RFID in the warehouse.

\subsection{Analysis}

Many academic literature reviews focus on bibliographical/statistical analysis that revolves around the categories, e.g. by type of journal, country, most cited institutions/individuals, etc. However, this study analyses the use of RFID technology in the warehouse, considering how and where it is applied to improve warehouse efficiency, what are the important benefits gained and its future trends to provide insights for new research scope and value-added business applications. This study area has been identified by Ngai et al. (2008) and Chao et al. (2007) as the next movement for researchers focusing on business values and organisational applications when the technology is reaching its maturity stage. The framework developed in this research builds upon the theoretical foundations from the strategy and information systems disciplines. These fields contributed significantly to the understanding of processes involved in the implementation of new technology, analysis of challenges to its adoption and benefits thereof (Whittaker et al., 2007; Dutta et al, 2007). To facilitate the analysis this paper is divided into four discussion topics as follows: 
- Discussion one: The application domains of RFID in different warehouse operations will be explored.

- Discussion two: A matrix will be produced to examine the benefits perceived.

- Discussion three: A discussion of the potential obstacles of adopting RFID in the warehouse.

- Discussion four: An analysis of the future trends that could further benefit the use of RFID in the warehouse.

In order to help academic and practitioner readers to better comprehend the key findings of the literature reviewed in this article, an RFID framework was developed (see Figure 2). It shows the application of the RFID in the warehouse, its benefits as well as the implementation obstacles related to this technology. Its categories are based on the analysis of the literature reviewed and the foundation of warehouse research. The framework is also aimed for facilitating the aforementioned four discussions.

\section{[Insert Figure 2]}

Figure 2 shows that there are several factors to consider during RFID implementation in the warehouse. The RFID technology can be implemented in all or only selected warehouse operations and there are several application domains to choose from. Furthermore, the RFID benefits and implementation obstacles can also be identified at first glance. The framework presented in Figure 2 could be a good reference for both academics and practitioners during their work on implementing RFID in the warehouse.

\section{Discussion One: Application of RFID in the Warehouse}

\subsection{Warehousing operations and their importance in the supply chain}

The efficiency and effectiveness of the supply chain network is depending on the performance of its functional elements, in particular, warehousing operations (Rouwenhorst et al., 2000). They facilitate storage and buffer functions between upstream and downstream points of the supply chain (de Koster, Le-Duc et al. 2007). The core warehouse operations revolve around the flow of materials in the facility, which are receiving, put away, storage, order picking and despatching (Gu et al., 2007, Berg and Zijm 1999). Receiving is the start of the warehousing process, in which the arriving items are unloaded from the transport carriers. Their identity, quantity and condition is checked at this stage, and items may be repacked to different stock keeping units, i.e. put into stillages, palletised or de-paletised, after which they await for the next process called put away. Put away is the process of physical moving of the received goods from the staging area to the locations in the warehouse, where they can be stored. Storage is the placement of goods in the facility for the purpose of safe keeping, protection and retrieval as required by the next activity. Order fulfilment or order picking refers to the removal of items from the storage locations for the purpose of fulfilling customer orders. Completed orders are checked to ensure picking accuracy and may be sorted or consolidated before despatching. Consolidation refers to grouping multiple orders for the same destination. Despatching is the last warehousing activity, in which goods are loaded onto the transport carrier. In addition to the aforementioned activities, warehouses also offer cross-docking function that coordinates products movement between receiving and despatching activities. Inbound cargo is sorted, combined with other inbound deliveries and despatched without being put to storage. Cross-docking operations serve the purpose of holding fewer inventory, reducing storage costs and improving service times (Maknoon et al., 
2009). Furthermore, warehouses may also perform a range of value-added processes, such as break-bulk, unpacking, testing, assembling, labelling and repacking.

Warehouse operations are critical in the supply chain management context (Lambert et al. 1998; de Koster, Le-Duc et al. 2007). Through their operations they address changing market conditions, and uncertainties of production and demand fluctuations. Moreover, they are capable of taking advantage of transportation and production economies, as well as allowing bulk quantity purchases to reduce procurement costs. Warehouses also serve as a buffer for activities like cross-docking, direct deliveries as well as reverse logistics whereby materials are collected for disposal or recycling. Additionally, warehouses create important link between suppliers and customers by overcoming space and time distance between them, allowing for maintaining desired customer service levels, consolidating multiple orders into one delivery and supporting just-in-time agreements between suppliers and customers.

\subsection{RFID literature analysis}

This paper performs an analysis on RFID publications corresponding to their application of the technology in the warehouse, which was a basis for the classifying framework. In the first step of this classification, based on the content of the articles two categories were formed: conceptual and implementation-focused application. The distinction between them is based on how the authors applied their research and findings. Articles demonstrating RFID application in warehouse environment at a company or laboratory facility were classified as "implementation-focused application". Whereas articles based on the results of software simulation, theory or proof of concepts, which did not state unambiguously about any application or test in a warehouse were put to "conceptual" category. There are 16 articles identified as implementation-focused applications and 42 articles that belong to conceptual category. This in itself highlights the lack of implementation-focused applications and the gap forming between these two categories.

By thoroughly analysing the articles, they were further grouped by their application domain and warehouse operation; some of them belong to more than one category (see Table 1). As depicted in Table 1, seven application domains were identified and in addition to the five typical warehouse operations a category "others" was included for articles of which the focus is on the general use of the technology in the warehouse. The 58 articles were then mapped with the appropriate RFID application domains and warehouse operations. To distinct between implementation-focused application and conceptual articles in each application domain, Figure 3 is produced. It can be noted that the domain of inventory/storage management has received the most attention whereby 24 articles have been published (17 being conceptual articles and 7 implementation-focused applications). The sequence of order is then followed by RFID system configuration (15 articles), MHE management (10 articles), WMS (9 articles), picker routing (8 articles), order management (6 articles), and lastly, layout with only 1 article. Table 1 can be further analysed with Figure 4 showing the number of research works in each warehouse operation. It can be seen in Figure 4 that most works (22 articles each) are related to receiving and storage operation, which coincide with Figure 3 whereby the biggest RFID application domain is inventory/storage management. The following subsections analyse the conceptual and implementation-focused categories based on RFID application domains.

[Insert Table 1]

[Insert Figure 3] 


\section{[Insert Figure 4]}

\subsection{Inventory/storage management}

According to Figure 3, the majority of authors focus on the use of RFID in inventory/storage management, which is the inherent part of core warehouse operation. It can be seen that the number of conceptual articles overgrow implementation-focused articles. The literature studied shows how RFID systems can benefit the warehouse in inventory and storage management, especially in the effort to resolve inefficiencies such as poor storage space utilisation, misplaced stocks, and wrong inventory records.

The conceptual articles present ideas or methods, some with supported simulation results, to envisage how RFID can be used in the warehouse. For instance, Ho et al. (2008) proposed an optimal methodology to solve the problem in relation to storage location assignment and used RFID to facilitate storage in a random and fragmented manner (i.e. enhancing the use and taking advantage of the benefits of employing random storage policy), and Hariharan et al. (2009) proposed Partially Observable Markov Decision Process model to enable quick detection of misplaced items in the warehouse using portable RFID devices or RFID-enabled forklift trucks. This helps to avoid wrong storage that leads to inventory inaccuracy, incomplete orders and subsequently, lost sales. Prior to implementation, it is common to use simulation software to evaluate new ideas. Rizzi et al. (2008) and Lu et al, (2007) used simulation approaches to redesign and test warehouse processes of a FMCG company and pallet movement systems respectively. Whereas Wang et al. (2008) and Wang et al. (2009) analysed processes at the mail and vegetable distribution centres respectively, pointing out how the introduction of RFID will impact the operations in these facilities.

As the technology advances, applications have been found incorporating RFID with other technologies/systems, on both software and hardware aspects. Software applications include a multi agent system used in the warehouse for controlling inventory and communicating with suppliers (García et al., 2007), rule based autonomous storage planning (Cheung et al., 2009), an RFID-based fuzzy storage assignment system (Ho et al., 2010) and a case based reasoning (Lao et al., 2010). The hardware aspect of RFID applications includes an unique method of material tracking (using RFID and IR) in the warehouse proposed by NEC (Naohisa et al., 2006). Other examples include Wang et al. (2010b) combining RFID with a novel design of conveyor belt system for storage and picking of items to fulfil customer orders and enables enhanced storage utilisation and Chuan et al. (2007) proposing a warehouse robot that uses RFID to identify objects and places in the warehouse by reading their tags and is able to navigate to designated locations. Furthermore, there are other creative proof of concept models, such as unmanned air vehicle (UAV) flying in the warehouse aisles for stock taking (Ong et al. 2007), RFID-enabled hand glove for locating lost items and counting inventory (Muguira et al., 2009) and tracking frequent walks of warehouse operatives or retail customers to reveal frequently visited spots in the facility (Berenyi et al. 2008).

The research work in implementation-focused articles involved developing a system for use in business applications. For instance, Wang et al. (2010a) developed Digital Warehouse Management System (DWMS), which consists of RFID-embedded pallets and shelves, to provide real-time visualised inventory control and automatic storage and retrieval. Liu et al. (2006) developed a resource management system to select the most suitable MHE to perform loading/unloading tasks in a lab-based warehouse facility. Since its introduction to the 
logistics field, RFID was considered as a promising technology that could improve operations not only within a company, but as a wider system connecting businesses. A number of implementation-focused articles presented such business-to-business (B2B) e-commerce with sharing RFID-collected inventory data. Bendavid et al. (2006) built a proof of concept model in the laboratory demonstrating inventory data collection from the process of despatching cargo to receiving at distribution centre. Other authors were also using similar B2B approach for inventory management in their respective supply chains, such as in beverage industry (Wamba et al. 2006), textile industry (Kwok and Wu 2009), and agricultural industry (Gandino et al. 2007; Zeimpekis et al., 2010).

\subsection{RFID system configuration}

Several studies were conducted to evaluate the configuration of RFID system in the warehouse, which resulted in the propositions of system set up. All articles studied are belonging to conceptual category, mainly focusing on testing their developing models to find the best system configuration and hopefully can be applied in implementation-focused. A general description of RFID system set up for warehouse consisting of tags, readers, middleware and WMS was provided by Li et al. (2009) and Modrak et al. (2010). The system configuration can be tuned depending on the specific requirements. For example, Choy (2009) presented a mathematical model for reconfiguring RFID systems, which takes into account of warehouse policies at pallet, case and combined levels. With this model decisions can be made regarding the hardware requirements for the RFID to be used in different warehouse applications. A variety of possible configurations is considered by Ross et al. (2009) whereby six scenarios were analysed and simulated, from barcode only to full RFID roll-out. The factors considered are labour utilisation, personnel and warehouse activity costs. While considering implementation strategies, it is important to reflect on the problems emerging during RFID roll-out at the warehouse. There are several factors influencing the feasibility of RFID system in warehouse operations that were tested by Porter et al. (2004), which included capture zone, orientation requirements, performance with MHE, performance when attached to different containers and content.

Another problem for RFID set up in the warehouse is regard to the entire facility coverage within the reader's range. A solution was proposed by Reza and Geok (2009) who developed square and hexagonal grids that ensure adequate coverage of desired areas with appropriate RFID signal. Similar radio waves propagation within facility was also undertaken by Bosselmann and Rembold (2006) whereby a ray tracing model was developed to visually show the areas where RFID signal was weak, so that tuning to ensure full coverage can be done. In order to be able to provide the functionality of RFID system despite incomplete readings, Hoong (2008) designed an experiment to find the least possible area for obtaining a full read rate of stacked cartons and this can be proved useful in setting up antennas positioning and tags reading. Likewise, the study on tagged carton containing metal and water moving on conveyor belt was conducted by Kabadurmus et al. (2007) and it was found that product type is a major factor contributing to RFID tag readability and fast conveyor speed being the second reason for tag misreading. This finding coincides with the study by Singh et al. (2008) and Singh et al., (2009) on palletised consumer goods, such as paper rolls, soda cans and water bottles. The variables identified were product type, pallet stacking pattern and forklift truck speed. Another factor impeding tag readability is the proximity of readers in a dense warehouse environment (Leong et al. 2006). A possible solution to this issue is proposed by Anssens et al., (2010) suggesting to synchronise readers' beam. 


\subsection{WMS}

There are considerable interests in investigating how RFID influences WMS and the effective methods of integration between them. Figure 3 shows 8 conceptual articles and one implementation-focused application article related to RFID-assisted WMS. Generally, WMS and RFID technology are integrated at three levels: data collection, data movement and data management (Tan, 2008). Data collection is realised by RFID readers communicating with WMS via IT network, and is analysed and used by WMS as part of data management. However, continuous stream of data in regard to identification and location of tags puts a strain of WMS causing long processing times. In order to alleviate this issue, at conceptual level Yang and Zou (2005) proposed an event-driven RFID reader management whereby data is sent to WMS on event triggered basis. This means that readers are only activated in the occurrence of detecting stock movements, and hence, only meaningful data is sent to WMS.

In addition, WMS may not be readily able to communicate with RFID system, thus it is necessary to add an additional software layer that will enable data exchange. Chu et al. (2008) proposed a way to integrate RFID middleware with WMS based on service-oriented architecture (SOA), converting RFID data to a recognisable format. Whereas Zhang et al. (2009) implemented procedures for reader management in Java programming language. According to Choy et al. (2008) another way to bring efficiency in WMS is to optimise database management with embedded procedures for handling queries efficiently, so as to enhance the performance of the entire system. Whereas for Qiu et al. (2005), an RFID-driven information flow system was proposed to address inefficient cycle counting, inaccuracy and costly labour. The one implementation-focused article is from Wang et al. (2010a) proposing DWMS which has been introduced in previous subsection.

\subsection{MHE management}

In contrast to previous application domains, there are more implementation-focused articles reported in MHE management. The only conceptual article is by Rizzi et al. (2008) developing business intelligent modules that execute rules for measuring key performance indicators and tracking of MHE activities in a FMCG company. In the implementationfocused use of RFID for tracking and routing MHE around the warehouse facility, there are several approaches proposed in the literature. Chow et al. (2006a) used ultra wideband (UWB) RFID system on forklift trucks to collect information about the state of the MHE, the problems with orders handling and the performance of warehouse resources. Similarly UWB was used in Chow et al. (2006b) and Chow et al. (2006c). Liu et al. (2006) applied WiFibased RFID system on the floor aisles to track cargo and MHE in real time in order to formulate an optimal strategy for order picking.

In order to ensure a smooth operation flow, the MHE must follow selected paths and all deviations from the routes must be recorded in order to improve future plans. Such system to manage MHE during order picking was developed by Poon et al. (2008), which consists of RFID-tagged forklifts and a network of readers covering the entire warehouse. The later work by the same authors (Poon et al., 2009) proposed an RFID case-based logistic resource management system to improve order picking by formulating appropriate material handling solutions based on triangular localisation scheme. In contrast to expensive real-time locating systems or embedding RFID tags in the warehouse flooring Jeon et al. (2010) suggested attaching tags to the warehouse ceiling in order to provide guidance for MHE. Guided maps for navigating MHE in order to improve routing and navigation around the facility were introduced by Prause et al. (2009) and Wang et al. (2010a). 


\subsection{Others (order management, picker routing and layout)}

There are six articles reported contributing to improving order management, five of which are implementation-focused articles which are the B2B models proposed by Bendavid et al. (2006) and Wamba et al. (2006), discussion of preliminary results of RFID pilot in Wamba et al. (2010), logistics management of dried figs (Zeimpekis et al., 2010), and three dynamic methodologies of order fulfilment introduced by Poon et al. (2009). There are only 8 articles reported to facilitate picker routing, i.e. RFID-enabled gloves (Muguira et al. 2009), an UWB system on forklifts (Chow et al. 2006abc) and tracking of warehouse staff movement (Berenyi et al. 2008ab), mobile assistance for warehouse workers (Prause et al., 2009) and RFID based system for solving optimally picking problem (Faschinger et al., 2007). The only article found for layout improvement is by Wang et al. (2010b) to fulfil customer orders efficiently through an RFID-enabled conveyor belt system.

\subsection{Types of RFID system in implementation-focused applications}

As part of the discussion, it is necessary to understand the type of RFID systems used in implementation-focused applications. To facilitate this understanding, Table 2 is populated. The table describes the implementation and application domains, and gives an overview of the type of frequency and communication protocol used, type of tags, and Electronic Product Code (EPC) compliance.

\section{[Insert Table 2]}

The UHF frequency has been a long standing choice for supply chain applications due to its long reading range and standardised protocol. This popularity is reflected in Table 2, whereby only two applications use HF tags. In Gandino et al. (2007), HF tags were used to identify fruit bins. Despite the unclear justification for this choice of frequency in the paper, it can be suggested that HF property of working well around water which is contained in fruits could well be the reason. In addition, Liu et al. (2006) used HF tags placed on the floor aisles for MHE positioning. It can be ascertained that in this case short reading range of HF tags was more suitable for this application to create more accurate paths for MHE, and to avoid interference with tags identifying stock. Most implementation-focused application articles use passive tags in their applications. The rationale for their choice is that they are inexpensive due to simpler tag design and components, and their appropriate reading range for the applications. Moreover, passive UHF tags can be standardised with ISO/EPC protocols. However, some applications may require active tags, e.g. in Chow et al. (2006abc) these tags were used to identify forklift trucks because of stronger signal and longer read range. Signal that is emitted by the active tag is strong to withstand interference from metal on forklift truck and provides a stable way for localising it during movement. As to the way readers communicate data from the tags to the middleware and WMS, several research works were conducted based on LAN network. The use of Wi-Fi networks was also investigated as it can cover warehouse space with minimum investment (i.e. using existing infrastructure).

Additionally, solutions offered by the market that have embedded LAN and Wi-Fi capabilities make it a viable way for transferring RFID-generated data. As far as the standardisation is concerned, only six articles mentioned the compliance with EPC standards, but it may be suggested from the widespread use of UHF passive tags that other applications in Table 2 would also comply with EPC standards. 


\section{Discussion Two: RFID Benefits Matrix}

In order to provide an insight for warehouse researchers and practitioners to assess the value of using RFID, scientific articles were analysed to present how RFID benefits were perceived. First, the articles were reviewed carefully to map with a list of benefits, as well as warehouse operations and application domains as previously discussed, so that a benefits matrix can be formed as seen in Table 3. Table 3 shows that majority articles reviewed in this study acknowledge more than one benefit of RFID and relate to more than one warehouse operation and application domain. The matrix was further analysed by means of associating the benefits with relevant warehouse operations and applications domains as shown in Tables 4 and 5 respectively. The benefits in the tables were ranked according to their perceived popularity based on the articles. This analysis approach is aimed at emphasising the high value benefits in the relevant warehouse operations and application domains, as well as highlighting the under-focused benefit areas that may lead to undertaking new research and developing new applications and solutions to improve warehouse operations.

\section{[Insert Table 3] \\ [Insert Table 4] \\ [Insert Table 5]}

There are a number of scholarly works discussing RFID achievements in the supply chain, identifying and assessing technology benefits. Tajima (2007) and Li and Visich (2006) proposed an extensive list of envisaged benefits within the supply chain context. Baars et al. (2009) suggested three key dimensions in which such benefits are realised: automation, information and transformation. These benefits can be direct or indirect and are affecting operational and managerial areas. The list of RFID benefits compiled was deriving from the previous works and was categorised in three warehouse relevant groups of benefits: product/resource related, operational and informational. Product/resource related benefits refer to the ones that impact on warehouse resources: storage space, equipment and handled products. Operational refer to the ones achieved in warehouse activities: reduced labour, lower costs, supply continuity, etc. and informational benefits are derived from the informational capabilities of RFID technology. These three main categories summarise areas where RFID has its impact on the warehouse.

In order to give a more thorough analysis, Table 3 also shows the percentage of the number of articles (from conceptual and implementation-focused applications categories) reported achieving the benefit in each benefit area. It is worth noting that the authors of this paper map the benefit only if it is clearly stated in the article as achieved, and avoid assumption predicting what benefit the article could have achieved. This is to ensure the quality and reliability of the analysis without prejudice.

Based on Table 3, it can be certain that many articles acknowledged more than one benefit received from a single RFID system implementation. This implies that the gains obtained from using RFID are interconnected between (and spread across different) operations/ domains, and hence a number of benefits can be achieved simultaneously. For example, product tracking is affecting various areas providing more benefits within the warehouse. Product tracking realised with the RFID allows for reducing shrinkages and better expiry date management. Additionally, knowing the location of the items helps to improve space utilisation and increase accuracy in product records, thus reducing inventory levels. Instant product identification realised with the RFID also helps to reduce the amount of manual labour, material handling and allows better exception management. Lastly, more accurate 
information about the products will enhance information sharing between the supply chain partners, helping in better determining arrival and despatch times.

In the early RFID literature the technology was touted to lower costs. This benefit was resulted from using RFID to reduce product shrinkages and stock-outs, to improve space utilisation and asset/resource management and to lower the inventory. Moreover, lower costs are also the outcome of reduced material handling and reduced labour through the use of the technology. Analysing the link between the reduced labour and other RFID benefits, it can be realised that it is a direct result of product tracking that gives increased data accuracy. This means that picking routes can be planned more efficiently and less time is spent on identifying items and their locations. Furthermore, reduced labour is also linked to improved asset/resource management, where less time is spent on locating MHE equipment within the warehouse, as well as reduced manual labour as breaking pallets is no longer required to identify items. These benefits may also result in offering better customer services, such as no stock-outs, better expiry date management for quality products, and product authentication.

The Table 3 also pointed out that the top benefits for implementation-focused application articles are lower costs (58\%), reduced labour (50\%), asset/research management (50\%), and increased data accuracy $(50 \%)$, whereas for conceptual articles they are product tracking (52\%), asset/resource management (40\%), reduced labour (19\%) and material handling $(17 \%)$. From these results, it has proved an evidence of relationship between identification as an essence of RFID technology and the benefits received. Recognising the unique identity of each object plays a crucial role in achieving the associated benefits above. For instance, with RFID in place, each pallet can be easily tracked and traced (i.e. product tracking), and warehouse operatives do not need to break down pallets to make identity and quantity checks (i.e. reduced labour time and cost). This also leads to facilitating material handling operations (i.e. good asset/resource management), and ensuring this information can be stored automatically on the back-end system/WMS eliminating laborious and error-prone manual data entry (i.e. increased data accuracy).

Tables 4 and 5 reveal the correlation between the benefits and warehouse operations and application domains respectively. The tables serve a twofold aim. Firstly, the tables show the well-perceived benefits and the most applied warehouse operations and application domains. This helps warehouse practitioners to identify a basis for investment justification. For instance, based on Tables 4 and 5 it can be identified that the benefits in the first third of the list are of high value and in addition, the storage operation (depicted in Table 4) and inventory/storage management (Table 5) have also received the most attention for RFID implementation/exploitation. Secondly, the less popular or overlooked benefits (especially the bottom third of the benefit list) and the under-focused warehouse operations and domains can also be identified. It was shown in earlier discussion that the RFID benefits are interconnected and this will give insights for the academics to form new research objectives and the practitioners to explore for potential value-added benefits.

\section{Discussion Three: RFID Obstacles in the Warehouse}

Despite the successful applications of RFID technology in the warehouse reported in industrial media (e.g. RFID Journal) and the promising academic research, there are a number of issues hindering the wide spread of RFID adoption in warehousing. Within the context of general application of RFID, Bose et al. (2009) suggested that issues impeding technology impact are related to adoption/acceptance, privacy/security, problem solving and contingency 
factors. Focusing on the echelons in the supply chain, Kapoor et al. (2009) discussed a number of RFID adoption obstacles related to the supply chain relationship (e.g. information ownership transfer, sharing cost of infrastructure and lack of economic incentives for information sharing) and technology specific (e.g. system bottlenecks due to data volume, risk of obsolescence of installed RFID solution, read errors and evolving standards). Similarly, RFID obstacles in warehouses are also related to adoption process, integration and technology performance. These obstacles can be classified into internal and external (see Figure 2). Internal obstacles refer to the problems encountered within the warehouse, starting with the decision to install RFID systems based on satisfactory return on investment (ROI), through to the concerns about integration with existing company legacy systems. RFID performance in the warehouse environment expands beyond an internal issue, as it is also depending upon the properties of the technology (which is considered to be an external obstacle). Matters of privacy and security are both internal and external, as on the one hand involve the warehouse management and employees and on the other, involve legislators and alike. The solely external obstacle affecting the RFID adoption in the warehouse is the issue of standardisation.

\subsection{Uncertain return on investment}

Return on investment (ROI) is one of the crucial criteria for companies to consider when introducing a new technology as this will point to their expectation on quantifiable benefits (Collins, 2004a). Several studies have reported concerns of some industries with lack of confidence that RFID could bring a satisfactory ROI (White et al, 2008; Attaran, 2007; Vijayaraman and Osyk, 2006; O'Connor, 2005). In order to justify the ROI for RFID implementation in the warehouse, the industry will need to assess what is critical to their businesses that will lead to maximum gains. Tables 4 and 5 provide a list of benefits together with their application domains and operations that can be used as a reference. For instance, achieving lower inventory combined with compact space utilisation may open a possibility for additional gains from renting out the freed storage space. Furthermore, reduced demand for labour along with reduction in material handling may lead to additional savings as a consequence of lower staff requirements. The more positive outlook on ROI was verified in recent study of the use of RFID in three echelon supply chain, which has illustrated the highest cost savings and satisfactory ROI in the warehouse (Giusto et al. 2010). The perception of unclear ROI and hesitance to invest in RFID may be changed by thorough evaluation of the application domains that will benefit the most in the warehouse facility, which will then create an opportunity for practitioners and researchers to identify new ways for efficiency enhancement, cost reduction and ROI improvement.

\subsection{Integration with legacy systems}

Another challenge to RFID adoption is the complexity of integration with the company's legacy systems, such as WMS, Enterprise Resource Planning (ERP), and Customer Relationship Management (CRM) (Vijayaraman and Osyk, 2006). This is also associated with the issue of handling the magnitude of data created by the integrated system. Without a common platform for exchanging data in different formats and high costs of system integration restrict the popularisation of the technology (Rim and Park, 2008). For example, RFID Journal reported on the problems International Paper encountered during RFID rolling out at one of its warehouses (Fleet, 2004). The company's legacy systems were written in COBOL, one of the oldest programming languages, and were not able to interact with the data generated by the new RFID system. The problem was solved using a layer interface that converted RFID data and presented it to the legacy systems as barcode data. RFID has a colossal impact on business IT system and its seamless integration with legacy systems will 
require enormous amount of planning in order to adapt the new integrated system with meaningful data in a reliable manner (Williams, 2005). The provision of such seamless integration is a great challenge; however it has the capability to significantly benefit a wide range of business operations.

\subsection{Failing RFID performance}

Another often mentioned obstacle to the widespread adoption of RFID is its performance (Wu et al., 2006). Several studies suggested that RFID does not provide 100\% reliable results in industrial settings (Collins, 2006b; Porter et al., 2004). In most cases, the reliability problems are related to the location of tags (Wu et al., 2006), signal distortions due to dense reader set up (Leong et al., 2006) and warehouse characteristics like metal parts and moving objects (Kabadurmus et al., 2007; Bosselmann and Rembold, 2006), as well as type of handled products (Singh et al., 2009). Deficient performance of the technology directly affects warehouse operations like receiving, picking and despatching, as these are the areas that require absolute confidence in product identification. Errors at each stage lead to discrepancies in WMS and inventory management, more time spent on order picking and disruption in service to customers; all resulting in more enquiries, investigations, returns, credit notes etc. Understandably, the practitioners have 100\% reliability expectation on RFID. However, some researchers suggested that reading performance at each stage of the warehouse operations does not have to be always $100 \%$ and a combination of actual and implied reads are sufficient to meet some purposes (Hardgrave and Miller, 2006). Ongoing improvements in the hardware aspect of RFID increase its capabilities and minimise deficiencies, but the perception of poor performance from earlier RFID experiences among practitioners may need time to overcome.

\subsection{Concerns about privacy and security}

The capability of RFID technology stimulated interest not only from academics and practitioners but also general public. The popular understanding of the technology suggests that RFID can continuously track people and objects anywhere and anytime, which created resistance and opposition to the technology (Hardgrave and Miller, 2006). For companies the question of privacy may be a concern in case of shared storage facility and when open loop RFID solutions are considered. It is reported that companies see a threat of industrial espionage through unauthorised tags reading (Roussos and Kostakos, 2009). Furthermore, as the RFID technology is affecting employees' roles it is perceived as a threat to job security (Curtin et al., 2007). Therefore, it is important to emphasise to the workforce that RFID adoption is to help workers in their tasks and improve productivity, not to cause redundancies or increase workload. Kwok and Wu (2009) suggested that inviting employees to participate in the RFID roll-out plan at early stages minimises their resistance to changes in company operations and may also result in better solutions. The privacy and security issues may be solved by increasing the protection measures embedded in the RFID hardware and software, while public privacy concerns about RFID may be alleviated by education and legislation.

\subsection{Standards development}

Early articles and studies about RFID noted the lack of unified global standards as an obstacle to widespread adoption of the technology (Vijayaraman and Osyk, 2006). However, at present the RFID standards exist are more established. The International Organization for Standardization (ISO) created standards for several RFID applications, such as animal tracking (ISO $11784 \& 11785$ ), contactless payments (ISO 14443), and vicinity cards (ISO 18047). Standards for testing conformance (ISO 18407) and performance (ISO 18046) of RFID tags and readers were issued. Additionally, a global standard for supply chain has also 
been developed. Electronic Product Code (EPC) is the core element of EPC Global Network proposed by GS1. Its second-generation protocol (Gen-2) was developed and approved by ISO, within ISO 18000 series. Although many RFID vendors are now complying with Gen-2 standard in order to promote wider adoption, some vendors are still using their proprietary protocol for specific purposes/applications. It is also important to note that power regulations and certification procedures are still varied from country to country.

\section{Discussion Four: Future Trends}

This section aims to explore the potential future trends and highlight a roadmap for the future through set of questions that need to be addressed, so as to expand the current RFID research scope and the commercial use of the technology in the warehouse. The topics for future trends presented in this section are based on the analysis above and the recent movement in the RFID market. Invaluable insight from the practitioners' perspective was gained through commercial literature, especially the recent reports in RFID Journal, as well as conversations with industry experts. There are four areas that could be conceivable domains for conducting RFID research from the warehousing perspective. They are open systems, data sharing, integration with other technologies and Internet of Things. All of these four areas are connected through the use of RFID, not as a single point of solution to solve operational problems within one organisation, but as a technology that spurs across the domains and links entities due to its informational and data sharing capabilities. Thus creating more closely linked and interconnected logistic systems. The following are some of the research questions on using the RFID technology based on the four areas:

- Considering warehouses as a part of the open supply chains based on RFID, what are the technological and operational implications for warehouses that need to be facilitated? What about other echelons in the supply chain? What models or theories on supply chain and warehousing designs, applications and benefits assessment would help logistics practitioners?

- What technological platforms could achieve seamless integration of RFID data across the supply chain? What would be the operational implications? How to encourage supply chain members to wider data sharing? What could be done to alleviate security threats and privacy concerns? What models and theories could help in evaluating and quantify the benefits of data sharing across the supply chain?

- What technologies currently used in warehouses could be enhanced with RFID? What could be done in order to ensure cost effectiveness of such integration? What would be the impact of RFID integration with other technologies on warehouse operations, productivity and costs? Would that meet the needs of warehousing practitioners?

- With the increase popularity of Internet of Things, what could be done to make warehouses part of this integrated system? What new models and practices could be developed? How to evaluate benefits of such integration and convey the benefits to the practitioners?

The following sub-sections explore potential future trends based on the analysis of literature in this article and the current situation in the RFID market.

\subsection{Open system}

It can be seen that majority of the research in the existing literature was conducted focusing on the benefits achieved in a single operation or operations within a warehouse (i.e. closed loop system), without expanding the research to how the technology could potentially benefit other supply chain partners (i.e. open system). RFID Journal has reported a range of cases 
deploying RFID as an infrastructure to bring greater improvements in the wider supply chain (RFIDJournal). As one of the core functions of RFID is unique identification of goods, more values can be achieved through close collaboration between supply chain partners as the goods move along the chain. For example, the downstream partners (e.g. retailers) can easily trace the status and location of their goods in the upstream supply chain and any discrepancy can be ramified immediately, in order to avoid stock-outs and hence increase sales and customer services. Furthermore, it can also prevent counterfeit products entering their supply chain. Another example is during the time of product recalls. Using RFID technology can make the process of recalling items faster and more efficient, as well as encourage trusts from the consumers. For instance, the application of RFID in tyre tracking during production, and in inventory management and aftermarket services (Wang et al., 2007). Similarly, Kumar and Budin (2006) presented an approach for product recalls in food industry. Such solution not only has the potential to provide the necessary identification in the case of product recalls, but it has also increased the efficiency of supply chain operations such as resource management in transportation and warehousing facility.

By opening up the view of using RFID in the supply chain, it can help the practitioners to see more values to achieve by collaborating with supply chain partners and the potential to reduce the overall cost of RFID investment, and hence stronger business cases for technology adoption can be justified. From the academic perspective, more research could be conducted focusing on the wider aspect supporting the technology applied in the supply chain and its technological and operational implications that need to be facilitated.

\subsection{Data sharing}

The ability to share RFID data is the key success of the technology. Data sharing is critical for applications in closed and open systems (Kwok and Wu, 2009; Wamba et al., 2006). For within a warehouse, it can be used for different departments/operations to achieve their purposes, e.g. quality control and expiry date management. These have been identified in Tables 4 and 5 as less popular benefits but value-added, which in this case, can be delivered. For an open system, the warehouse operator will need to know the manufacturer's production status in order for them to prepare the storage facility needed, so does the transportation to ensure their service availability. Any of the irregularities in the supply can be immediately detected. Another benefit closely connected to data sharing is exception management. Swift identification with RFID enables alerting warehouse staff to expected special (urgent despatching) products, which in other cases would not be given the priority. Sharing data about stock between warehouses and supply chain partners helps to avoid high inventory (safety stock) levels. Moreover, better determining of stock arrival and despatch times can also be realised, resulting from the ability of reading RFID tags at different stages in the supply chain (Bendavid et al., 2006).

To enhance data sharing across the supply chain, the practitioners could utilise a central data sharing system such as EPC Information System (Osinski, 2009). With EPCIS, each supply chain partner can easily access to the acquired data. However, much research will be needed focusing on a common (technical) platform whereby each key operation at the supply chain partners can be seamlessly incorporated, e.g. to create a communication channel for instant notification of action.

\subsection{Integration with other technologies}

As any technology emerging, more features will be expected by the users. This can be seen when one technology integrates with another so that better features can be introduced and less 
infrastructure changes can be made possible. In RFID market, to enhance its adoption there are integrations with $\mathrm{Wi}-\mathrm{Fi}$, GPS and infrared for various applications. In warehousing, RFID integration with, e.g. pick-to-light and voice-assisted picking systems, will lead to more efficient storing and order picking. One should explore new ways of integrating different technologies in warehousing facility in order to maximise operational efficiency and much research should be conducted to address the technical and operational challenges for such integration solutions.

\subsection{Internet of Things}

The Internet of Things (IoT) has been a popular topic in recent years, significantly supported by many governments. Within the Seventh Framework Programme, the European Commission is supporting a number of research projects on IoT. In China, Wuxi City is named as the National Innovation Demonstration Zone of IoT (Iera et al., 2010). In essence, IoT consists of a network of autonomous nodes (e.g. systems, technologies, applications) but yet connected through a common platform and that are capable of communicating with each other to provide a wide range of services to make our lives easier. RFID can play an important role in this network as a means of communication and data provider. In terms of warehouse/RFID research, there is a range of domains worth exploiting, such as data interchange mechanism, compatibility between different systems/Internet technologies, adaptable B2B model, and so on.

\section{Concluding Remarks}

This paper provided a comprehensive analysis of the academic literature published from 1995 to 2010 pertaining to the application of RFID technology in warehouses based on the perceived benefits, application domains and warehouse operations. The paper was organised into four discussion topics, aiming to analyse the current state of RFID application in the warehouse and provide insights for the academics to establish new research domains and for the practitioners to evaluate their assessment of adopting RFID in the warehouse. To the best of authors' knowledge, this study is the first identifiable review of academic literature about RFID application in the warehouse function. Previous works were an overall reviews of the literature (Ngai, et al., 2008; Chao et al., 2007) or specifically focused on supply chain management (Sarac, et al., 2010). Ngai et al. (2008) suggested the future increase in the number of the published literature on RFID and this study confirmed the continuation of this trend (see Figure 1), but it was found that particular interest in RFID in warehousing is rather stagnant and relatively small in comparison to other research domains. Ngai et al. (2008) noted that RFID research focuses on internal operations (i.e. closed loop system) and given a recommendation for opening it up to include a wider scope of benefits that may be achieved in the value chain. It emerged that the majority of articles reviewed in this study was also focused on the benefits achieved in a single operation or operations within a warehouse. Therefore, the authors of this study would like to stress the recommendations, given in previous section, for expanding the research to how the technology could potentially benefit other supply chain partners.

As for the reasons impeding RFID applications, technical and economic difficulties discussed in Sarac et al. (2010) were also confirmed in this study. Despite the similarity of insights with general and supply chain management RFID reviews of the scientific field, this article identified the gaps and findings that are specific to the warehouse research. The prior RFID warehouse research reviewed in this study was divided to two categories: implementationfocused applications and conceptual papers. Articles in the first category showed how RFID 
is applied in the various warehouse functions, and specifically dealt with practicalities of the application. Whereas conceptual papers proposed ideas for improvements and extended the use of the technology with findings based on computer simulation, theory or proof of concept.

This study identified several key findings/gaps that could be covered in the future warehouse research. First of all, it was pointed out that researchers' focus is revolving around the applications and benefits that are closely linked to "identification", which is the core function of RFID technology. This study has also revealed various associated benefits of RFID that are scarcely examined in the literature. It is envisaged that studies showing linkage between RFID benefits could strengthen the case for RFID adoption. Secondly, RFID solutions are treated as a closed loop system and its benefits are less exploited across the supply chain, in spite of recommendations in the earlier works. To facilitate the exploration of wider adoption in the supply chain, this study discussed the potential RFID obstacles that could hold up the adoption decisions. Furthermore, this study also indicated and discussed the potential future trends that could lead to further research directions and new, creative applications for commercial use.

Apart from providing useful analysis of RFID literature to the academic community, this article offers some key lessons for the practitioners. To begin with, this study can be used as a reference library to identify specific RFID warehouse applications, which have been classified by warehouse operation, application domain and benefits discussed. The analysis of the implementation-focused RFID applications may be of key interest to industry executives, as it does not only provide a summary of how the RFID technology is used in warehouses, but also point out technical details of each application. This could serve as guidance in their plans to implement RFID and their business case may be strengthened by a list of interrelated RFID benefits that could be achieved in the warehouse. Lastly, the discussion on RFID obstacles in the warehouse may help to avoid pitfalls en route to successful RFID adoption.

Building a strong business case for RFID adoption in the warehousing industry will require expanding from the current state to more value-added applications in the emerging market. There are several ways for the data generated by RFID to benefit warehouse operations. One of them is to use the data for cost analysis of the performed operations. The authors of this paper are currently developing a dynamic cost optimisation framework for WMS that will evaluate all associated costs of warehouse operations based on RFID data, so as to fulfil customers' order requirements more efficiency and cost-effectively. In conclusion, the authors would like to encourage academics and industry researchers to look beyond the core applications for RFID and consider more overarching applications that will take RFID benefits beyond the current state, e.g. being able to support the up and coming realisation of IoT.

\section{Acknowledgements}

This study is part of a work package of a project sponsored by the UK Engineering and Physical Science Research Council (EP/H048936/1). The authors would also like to express their appreciation to the members in RFID Advanced Research for their contribution to this study. 


\section{References}

Anonymous, 2005. The pros and cons of RFID: Data analysis. Strategic Direction 21, 24-26.

Anssens, C., Rolland, N. \& Rolland, P.-. 2010, "RFID reader's synchronization to get a coordinated beam direction for warehouse application", European Microwave Week 2010, EuMW2010: Connecting the World, Conference Proceedings - European Microwave Conference, EuMC 2010, pp. 1102.

Attaran, M., 2007. RFID: an enabler of supply chain operations. Supply Chain Management $12,249-257$.

Baars, H., Gille, D. \& Struker, J. 2009. Evaluation of RFID applications for logistics: a framework for identifying, forecasting and assessing benefits. Eur J Inf Syst, 18, 578-591.

Bacheldor, B., 2006. Unilever Expects Big Gains From Its RFID Data-Sharing Trial. RFID Journal, http://www.rfidjournal.com/article/view/2551/1/1/ [Accessed: 2011-01-16].

Bahr, W., Lim, M.K., 2009. Implementation challenges of application of radio frequency identification (RFID) in warehouse, in: Macchi, M., Pinto, R. (Eds.), 11th International Conference on the Modern Information Technology in the Innovation Processes of the Industrial Enterprises. Università degli Studi di Bergamo, Bergamo, Italy.

Bendavid, Y., Wamba, S.F., Lefebvre, L.A., 2006. Proof of concept of an RFID-enabled supply chain in a B2B e-commerce environment, in: Spencer, B., Fox, M.S., Du, W., Du, D., Buffett, S. (Eds.), 2006 ICEC: Eighth International Conference on Electronic Commerce, Proceedings - The New E-Commerce: Innovations For Conquering Current Barriers, Obstacles And Limitations To Conducting Successful Business On The Internet, 564-568.

Berenyi, Z., Charaf, H., 2008a. Retrieving frequent walks from tracking data in RFIDequipped warehouses, IEEE Conference on Human System Interactions 1- 2, 669-673.

Berenyi, Z. \& Charaf, H. Utilizing Tracking Data in RFID-Equipped Warehouses. In: Communications Workshops, 2008b. ICC Workshops '08. IEEE International Conference on, 19-23 May 2008 2008. 169-173.

Berg, J. P. V. D. \& Zijm, W. H. M. 1999. Models for warehouse management: Classification and examples. International Journal of Production Economics, 59, 519-528.Models for warehouse management: Classification and examples. International Journal of Production Economics, 59, 519-528.

Bose, I., Ngai, E. W. T., Teo, T. S. H. \& Spiekermann, S. 2009. Managing RFID projects in organizations. European Journal of Information Systems, 18, 534-540.

Bosselmann, P., Rembold, B., 2006. Investigations on UHF RFID wave propagation using a ray tracing simulator. Frequenz 60, 38-45.

Brown, M., Patadia, S., Dua, S., Meyers, M., 2007. Mike Meyers' Comptia RFID+ Certification Passport. McGraw-Hill Osborne Media. 
Burnell, J., 2009. Sam's Club Letter Outlines Changes to RFID Requirements, RFID Journal, http://www.rfidjournal.com/article/view/7109 [Accessed: 2011-01-16].

Chao, C.-C., Yang, J.-M., Jen, W.-Y., 2007. Determining technology trends and forecasts of RFID by a historical review and bibliometric analysis from 1991 to 2005 . Technovation 27, 268-279.

Cheung, M. Y. Y., Choy, K. L., Tan, K. H., Lau, H. C. W. \& Choy, E. L. H. 2009. The design of an RFID-enhanced autonomous storage planning system for 3PL warehouses. International Journal of Value Chain Management, 3, 108-128.

Chow, H.K.H., Choy, K.L., Lee, W.B., Lau, K.C., 2006a. Design of a RFID case-based resource management system for warehouse operations. Expert Systems with Applications $30,561-576$.

Chow, K. H., Choy, K. L. \& Lee, W. B. 2006b. Design of a knowledge-based logistics management system: a case-based RFID approach. International Journal of Enterprise Network Management, 1, 5-28.

Chow, K. H., Choy, K. L. \& Lee, W. B. 2006c. On the design of a real-time knowledge-based system for managing logistics operations. Intelligent Systems in Accounting, Finance and Management, 14, 3-25.

Choy, K.L., 2009. A design method for configuration and setup of a RFID system in a warehouse, in: Kocaoglu, D.F., Anderson, T.R., Daim, T.U., Jetter, A., Weber, C.M. (Eds.), Proceedings of Picmet 09 - Technology Management in the Age of Fundamental Change 1-5, 2199-2204.

Choy, K.L., Choy, E.L.H., Poon, T.C., 2008. A real-time database management system for logistics systems: A case study, IEEE Portland International Conference on Management of Engineering \& Technology 1-5, 864-871.

Chu, W.J., Li, W.P., 2008. Study of integrating RFID middleware with enterprise applications based on SOA, IEEE 4th International Conference on Wireless Communications, Networking and Mobile Computing 1-31, 6903-6906.

Chuan, L.P., Johari, A., Wahab, M.H.A., Nor, D.M., Taujuddin, N., Ayob, M.E., 2007. An RFID warehouse robot, ICIASs 2007: IEEE International Conference on Intelligent \& Advanced Systems 1-3, 451-456.

Collins, J., 2004a. RFID's ROI Tops User Concerns, RFID Journal, http://www.rfidjournal.com/article/view/1207 [Accessed: 2011-01-16].

Collins, J., 2004b. Tesco Begins RFID Rollout, RFID Journal, http://www.rfidjournal.com/article/view/1139 [Accessed: 2011-01-16].

Collins, J., 2006a. P\&G Finds RFID 'Sweet Spot', RFID Journal, http://www.rfidjournal.com/article/view/2312 [Accessed: 2011-01-16]. 
Collins, J., 2006b. RFID Implementation Is an Art, RFID Journal, http://www.rfidjournal.com/article/articleview/2427/1/1/ [Accessed: 2011-01-16].

Curtin, J., Kauffman, R., Riggins, F., 2007. Making the 'MOST' out of RFID technology: a research agenda for the study of the adoption, usage and impact of RFID. Information Technology and Management 8, 87-110.

De Koster, R., Le-Duc, T. \& Roodbergen, K. J. 2007. Design and control of warehouse order picking: A literature review. European Journal of Operational Research, 182, 481-501.

Ding, B., Chen, L., Chen, D.L., Yuan, H.T., 2008. Application of RTLS in warehouse management based on RFID and Wi-Fi, IEEE 4th International Conference on Wireless Communications, Networking and Mobile Computing 1-31, 5229-5233.

Dortch, M., 2008. Where RFID Meets ROI: Beyond supply chains, Aberdeen Group, http://www.fluensee.com/downloads/Aberdeen_Report_RFID_Meets_ROI.pdf [Accessed: 2011-01-16].

Dutta, A., Lee, H. L. \& Whang, S. 2007. RFID and Operations Management: Technology, Value, and Incentives. Production and Operations Management, 16, 646.

Fabian, B., Oliver, G., 2009. Security challenges of the EPCglobal network. Communications of the ACM 52, 121-125.

Faschinger, M., Sastry, C. R., Patel, A. H. \& Tas, N. C. An RFID and wireless sensor network-based implementation of workflow optimization. In: World of Wireless, Mobile and Multimedia Networks, 2007. WoWMoM 2007. IEEE International Symposium on a, 18-21 June 2007 2007. 1-8.

Fleet, S.V., 2004. Case Study: International Paper, RFID Journal, http://www.rfidjournal.com/article/articleview/890 [Accessed: 2011-01-16].

Gandino, F., Montrucchio, B., Rebaudengo, M., Sanchez, E.R., 2007. Analysis of an RFIDbased information system for tracking and tracing in an agri-food chain, in: Ozok, A.F., Ustundag, A. (Eds.), Proceedings of the 1st RFID Eurasia Conference, 143-148.

García, A., Chang, Y., Abarca, A. \& Oh, C. 2007. RFID enhanced MAS for warehouse management. International Journal of Logistics Research and Applications, 10, 97-107.

Giusto, D., Iera, A., Morabito, G., Atzori, L., Bertolini, M., Bottani, E., Rizzi, A., Volpi, A., 2010. The Benefits of RFID and EPC in the supply chain: Lessons from an Italian pilot study, The Internet of Things. Springer New York, 293-302.

Hardgrave, B.C., Miller, R., 2006. The myths and realities of RFID. International Journal of Global Logistics and Supply Chain Management 1, 1-16.

Hariharan, S., Bukkapatnam, S.T.S., 2009. Misplaced item search in a warehouse using an RFID-based Partially Observable Markov Decision Process (POMDP) model, IEEE International Conference on Automation Science and Engineering, 443-448. 
Ho, S.S., Sarma, S., 2008. The fragmented warehouse: Location assignment for unit-load picking, IEEE International Conference on Industrial Engineering and Engineering Management, 1-3, 1159-1163.

Ho, G. T. S., Choy, K. L. \& Poon, T. C. Providing decision support functionality in warehouse management using the RFID-based fuzzy association rule mining approach. In: 8th International Conference on Supply Chain Management and Information Systems: Logistics Systems and Engineering, SCMIS 2010, 6-8 October 20102010 Hong Kong.

Holmes, P., 2005. Will tags get out into the supply chain, Works Management.

Hoong, E.C.M., 2008. Shortest travel distance for full reads on least RFID friendly carton stacking configuration using advance DOE techniques and gage reproducibility and repeatability, 2008 IEEE International Conference on RFID, 223-231.

Hunt, V.D., Puglia, M., Puglia, A., 2007. A guide to radio frequency identification. John Wiley \& Sons Inc.

Iera, A., Floerkemeier, C., Mitsugi, J., Morabito, G., 2010. The Internet of Things [Guest Editorial]. IEEE Wireless Communications 17(6), 8-9.

Jeon, S., Choi, M., Gihong, K. \& Bonghee, H. Localization of Pallets Based on Passive RFID Tags. In: Information Technology: New Generations (ITNG), 2010 Seventh International Conference on, 12-14 April 2010. 834-839.

Kabadurmus, O., Kilinc, S., Behret, H., Uygun, G., 2007. Performance evaluation of operational parameters on RFID controlled conveyor system, in: Ozok, A.F., Ustundag, A. (Eds.), Proceedings of the 1st RFID Eurasia Conference, 307-312.

Kapoor, G., Zhou, W. \& Piramuthu, S. 2009. Challenges associated with RFID tag implementations in supply chains. European Journal of Information Systems, 18, 526-533.

Kumar, S. and Budin, E.M., 2007. Prevention and management of product recalls in the processed food industry: a case study based on an exporter's perspective. Technovation 25 (5-6), 739-750.

Kwok, S.K., Wu, K.K.W., 2009. RFID-based intra-supply chain in textile industry. Industrial Management \& Data Systems 109, 1166-1178.

Lambert, D. M., Stock, J. R. \& Ellram, L. M. 1998. Fundamentals of logistics management, Irwin/McGraw-Hill Boston.

Lao, S.I., Choy, K.L., Tsim, Y.C. \& Poon, T.C. 2010, "A RFID-based decision support system for food receiving operations assignment", SCMIS 2010 - Proceedings of 2010 8th International Conference on Supply Chain Management and Information Systems: Logistics Systems and Engineering.

Leong, K.S., Ng, M.L., Grasso, A.R., Cole, P.H., 2006. Synchronization of RFID readers for dense RFID reader environments, in: Werner, B. (Ed.), International Symposium on Applications and the Internet Workshops, Proceedings, 48-51. 
Li, C.H., He, Q., IEEE, 2009. Design for the logistics storage management system based on RFID, Proceedings of the 3rd International Conference on Anti-Counterfeiting, Security, and Identification in Communication, 215-218.

Li, S., Visich, J.K., 2006. Radio frequency identification: supply chain impact and implementation challenges. International Journal of Integrated Supply Management 2, 407 424.

Liu, G.D., Yu, W.S., Liu, Y., 2006. Resource management with RFID technology in automatic warehouse system, 2006 IEEE/RSJ International Conference on Intelligent Robots and Systems 1-12, 3706-3711.

Luckett, D., 2004. The supply chain. BT Technology Journal 22(3), 50-55.

Meho, L.I., Yang, K., 2007. Impact of data sources on citation counts and rankings of LIS faculty: Web of Science versus Scopus and Google Scholar. Journal of the American Society for Information Science and Technology 58, 2105-2125.

Maknoon, M. Y. \& Baptiste, P. 2009. Cross-docking: increasing platform efficiency by sequencing incoming and outgoing semi-trailers. International Journal of Logistics Research and Applications: A Leading Journal of Supply Chain Management, 12, 249 - 261.

Modrak, V., Knuth, P. \& Sebej, P. 2010. Adoption of RFID technology in warehouse management. Communications in Computer and Information Science. Springer Verlag.

Muguira, L., Vazquez, J.I., Arruti, A., de Garibay, J.R., Mendia, I., Renteria, S., 2009. RFIDGlove: a Wearable RFID Reader, in: Chung, J.Y., Guo, J., Nazaraf, S. (Eds.), Icebe 2009: IEEE International Conference on E-Business Engineering, Proceedings, 475-480.

Naohisa, H., Naoki, I., Masao, I., Mitsunori, M., Kon'ichi, I., 2006. Assets location management solution based on the combination of SmartLocator and RFID. NEC Technical Journal 1, 92-96.

Narsing, A., 2004. RFID and supply chain management - An assessment of its economic and productive viability in global operations, in: Swan, N. (Ed.), Managing in a Dangerous World - Twenty-Five Years of Technical Conferences: Bridging Between Technology And Management, 95-99.

Ngai, E.W.T., Karen, K.L.M., Frederick, J.R., Candace, Y.Y., 2008. RFID research: An academic literature review (1995-2005) and future research directions. International Journal of Production Economics 112, 510.

O'Connor, M.C., 2005. Most RFID Users Believe RFID Lacks ROI, RFID Journal, http://www.rfidjournal.com/article/view/1753 [Accessed 2011/01/16].

O'Connor, M.C., 2008. Wal-Mart, DOD Point to Sustained Progress, RFID Journal, http://www.rfidjournal.com/article/view/4407 [Accessed: 2011/01/16]. 
Osinski, T., 2009. How to Realize the Full Potential of EPCIS, RFID Journal, http://www.rfidjournal.com/article/print/4627 [Accessed: 2011/02/16].

Oztaysi, B; Baysan, S; Akpinar, F , 2009. Radio frequency identification (RFID) in hospitality. Technovation 29 (9), 618-624.

Poon, K.T.C., Choy, K.L., Lau, H.C.W., 2008. A RFID-based location tracking scheme for inbound operations in warehouse environment, 2008 Portland International Conference on Management of Engineering \& Technology, 1-5, 872-877.

Poon, T.C., Choy, K.L., Chow, H.K.H., Lau, H.C.W., Chan, F.T.S., Ho, K.C., 2009. A RFID case-based logistics resource management system for managing order-picking operations in warehouses. Expert Systems with Applications 36, 8277-8301.

Porter, J.D., Billo, R.E., Mickle, M.H., 2004. A standard test protocol for evaluation of radio frequency identification systems for supply chain applications. Journal of Manufacturing Systems 23, 46-55.

Prause, C.R., Eisenhauer, M. \& Gillmann, L. 2009, "Industrial case study of the MICA support system for warehouse workers", ACM International Conference Proceeding Series.

Reza, A.W., Geok, T.K., 2009. Objects tracking in a dense reader environment utilising grids of RFID antenna positioning. International Journal of Electronics 96, 1281-1307.

Pramatari, K. \& Theotokis, A. 2009. Consumer acceptance of RFID-enabled services: a model of multiple attitudes, perceived system characteristics and individual traits. European Journal of Information Systems, 18, 541-552.

RFIDJournal, Two Ways to Think about RFID (Podcast), http://www.rfidjournal.com/article/view/3848/1/1/ [Accessed: 2011/01/16].

Rim, S.C., Park, I.S., 2008. Order picking plan to maximize the order fill rate. Computers \& Industrial Engineering 55, 557-566.

Rizzi, A., Montanari, R., Volpi, A., Tizzi, M., 2008. Reengineering and simulation of an RFID manufacturing system, in: Haasis, H.D., Kreowski, H.J., ScholzReiter, B. (Eds.), Dynamics in Logistics, 211-219.

Roberti, M., 2006. RFID Adoption Is Spreading, RFID Journal, http://www.rfidjournal.com/article/articleview/2619/1/128/ [Accessed: 2011/01/16].

Ross, A.D., Twede, D., Clarke, R.H., Ryan, M., 2009. A framework for developing implementation strategies for a radio frequency identification (RFID) system in a distribution center environment. Journal of Business Logistics 30, 157-183.

Roth, D.L., 2005. The emergence of competitors to the Science Citation Index and the Web of Science. Current Science 89, 1531-1536.

Roussos, G., Kostakos, V., 2009. RFID in pervasive computing: State-of-the-art and outlook. Pervasive and Mobile Computing 5, 110-131. 
Rouwenhorst, B., Reuter, B., Stockrahm, V., Van Houtum, G. J., Mantel, R. J. \& Zijm, W. H. M. 2000. Warehouse design and control: Framework and literature review. European Journal of Operational Research, 122, 515-533.

Sarac, A., Absi, N. \& Dauzère-Pérès, S. 2010. A literature review on the impact of RFID technologies on supply chain management. International Journal of Production Economics, $128,77-95$.

Singh, S. P., Mccartney, M., Singh, J. \& Clarke, R. 2008. RFID research and testing for packages of apparel, consumer goods and fresh produce in the retail distribution environment. Packaging Technology and Science, 21, 91-102.

Singh, J., Olsen, E., Vorst, K., Tripp, K., 2009. RFID tag readability issues with palletized loads of consumer goods. Packaging Technology and Science 22, 431-441.

Son, B.K., Lee, J.H., Park, K.L., Kim, S.D., 2007. An efficient management algorithm for gateway readers in the warehouse, in: Kim, S.S., Park, J.H., Pissinou, N., Kim, T.H., Fang, W.C., Slezak, D., Arabnia, H.R., Howard, D. (Eds.), MUE: 2007 International Conference on Multimedia and Ubiquitous Engineering, Proceedings, 130-134.

Tajima, M., 2007. Strategic value of RFID in supply chain management. Journal of Purchasing \& Supply Management 13, 261-273.

Tan, H., 2008. The application of RFID technology in the warehouse management information system, Proceedings of the International Symposium on Electronic Commerce and Security, Guangzhou, China, 1063-1067.

Twist, D.C., 2005. The impact of radio frequency identification on supply chain facilities. Journal of Facilities Management 3, 226-239.

Uckun, C., Karaesmen, F., Savas, S., 2008. Investment in improved inventory accuracy in a decentralized supply chain. International Journal of Production Economics 113, 546-566.

Vijayaraman, B.S., Osyk, B.A., 2006. An empirical study of RFID implementation in the warehousing industry. International Journal of Logistics Management 17, 6-20.

Wamba, S.F., Lefebvre, L.A., Lefebvre, E., 2006. Enabling intelligent B-to-B eCommerce supply chain management using RFID and the EPC network: A case study in the retail industry, in: Spencer, B., Fox, M.S., Du, W., Du, D., Buffett, S. (Eds.), 2006 ICEC: Eighth International Conference on Electronic Commerce, Proceedings - The New E-Commerce: Innovations For Conquering Current Barriers, Obstacles And Limitations To Conducting Successful Business On The Internet, 281-288.

Wamba, S. F. \& Boeck, H. 2008. Enhancing information flow in a retail supply chain using RFID and the EPC network: A proof-of concept approach. Journal of Theoretical and Applied Electronic Commerce Research, 3, 92-105. 
Wamba, S. F. \& Chatfield, A. T. RFID-Enabled Warehouse Process Optimization in the TPL Industry. In: System Sciences (HICSS), 2010 43rd Hawaii International Conference on, 5-8 Jan. 2010. 1-10.

Wang, H.W., Chen, S., Xie, Y., 2010a. An RFID-based digital warehouse management system in the tobacco industry: a case study. International Journal of Production Research 48, 2513-2548.

Wang, Q., McIntosh, R., Brain, M., 2010b. A new-generation automated warehousing capability. International Journal of Computer Integrated Manufacturing 23, 565 - 573.

Wang, Y.Y., Wu, Y.H., Liu, Y.Y., Tang, A.J., 2007. The application of radio frequency identification technology on tires tracking, IEEE International Conference on Automation and Logistics, 1-6, 2927-2930.

Wang, Z., Kim, M., Koo, H. Y. \& Bae, H. Process improvement evaluation in mail distribution center by applying RFID technology. In: 3rd International Conference on Innovative Computing Information and Control, ICICIC'08, 2008 Dalian, Liaoning.

Wang, J. \& Bao, L. 2009, "Study on the optimal internal processes designing of vegetable distribution center based on tracing information collection of material flow", Proceedings 2009 International Forum on Information Technology and Applications, IFITA 2009, pp. 271.

Wessel, R., 2008. Metro Group, DHL to Roll Out RFID in France, RFID Journal, http://www.rfidjournal.com/article/view/4277 [Accessed: 2011/01/16].

White, A., Johnson, M., Wilson, H., 2008. RFID in the supply chain: lessons from European early adopters. International Journal of Physical Distribution \& Logistics Management 38, 88-107.

Whitaker, J., Mithas, S. \& Krishnan, M. S. 2007. A Field Study of RFID Deployment and Return Expectations. Production and Operations Management, 16, 599.

Williams, D.H., 2005. IT's Impact on RFID, RFID Journal, http://www.rfidjournal.com/article/view/1648 [Accessed: 2011/01/16].

Wu, N.C., Nystrom, M.A., Lin, T.R., Yu, H.C., 2006. Challenges to global RFID adoption. Technovation 26, 1317-1323.

Yan, B., Chen, Y.Y., Meng, X.S., 2008. RFID technology applied in warehouse Management system, in: Chen, Y.J., Zhou, Q.H. (Eds.), ISECS International Colloquium on Computing, Communication, Control, and Management 3, 363-367.

Yang, D.Y., Zou, P., 2005. Event driven RFID reader for warehouse management, in: Shen, H., Nakano, K. (Eds.), PDCAT 2005: Sixth International Conference on Parallel and Distributed Computing, Applications and Technologies, Proceedings, 895-899. 
Zeimpekis, V., Minis, I. \& Pappa, V. 2010. Real-time logistics management of dried figs using RFID technology: case study in a Greek cooperative company. International Journal of Logistics Systems and Management, 7, 265-285.

Zhang, M., Li, W.F., Wang, Z.Y., Li, B., Ran, X., 2007. A RFID-based material tracking information system, IEEE International Conference on Automation and Logistics, 1-6, 29222926.

Zhang, M., Batta, R., Nagi, R., 2008. Modeling of workflow congestion and optimization of flow routing in a manufacturing/warehouse facility. Management Science 55(2), 267-280.

Zhang, Q., Cheng, G., Wang, Z., Wei, J. \& Yan, D. Development of RFID application system in cargo inbound and outbound. In: TENCON 2009 - 2009 IEEE Region 10 Conference, 2326 Jan. 2009. 1-6. 


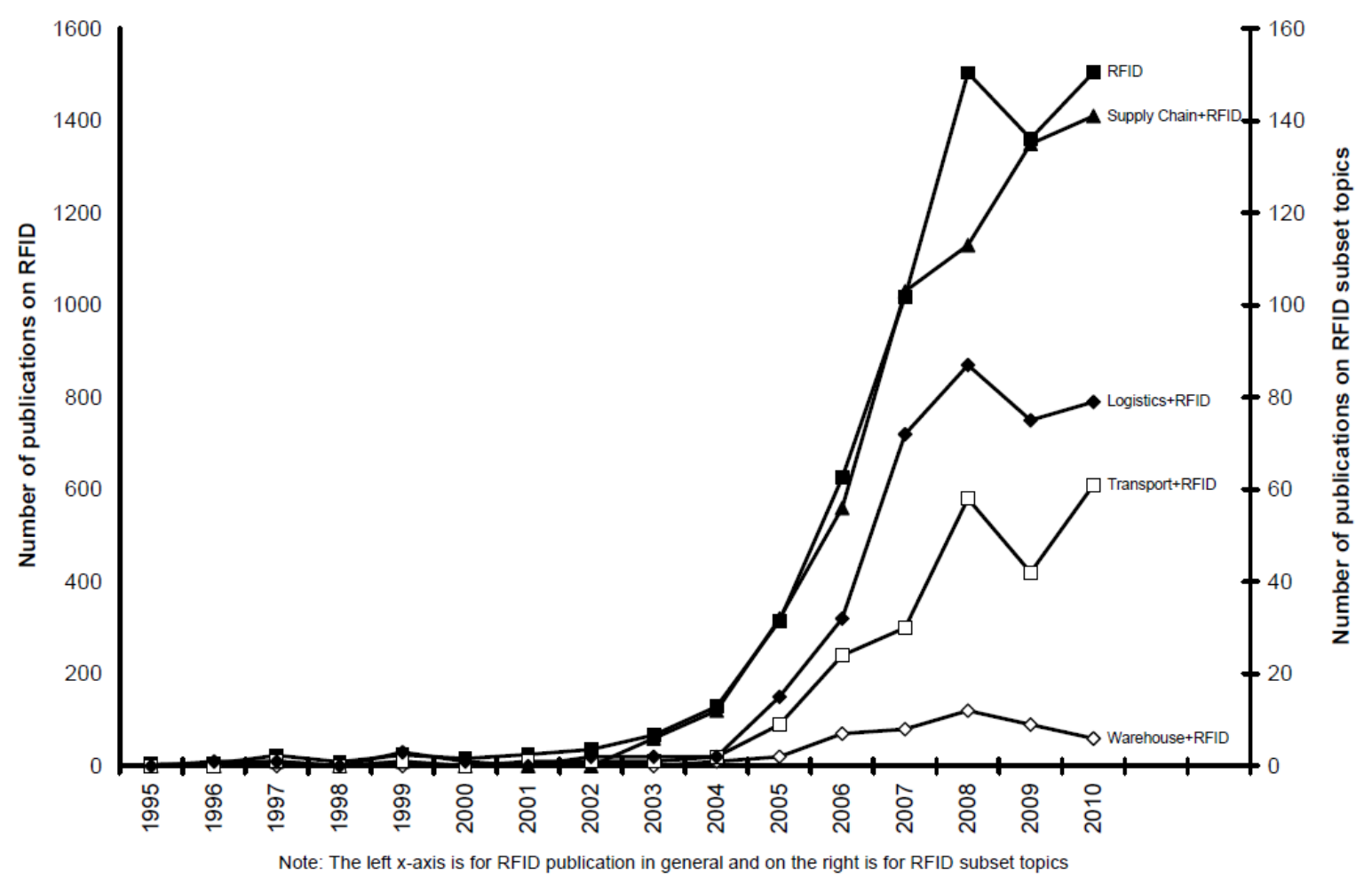

Figure 1. Publications from 1995 to 2010 on RFID and subset topics 


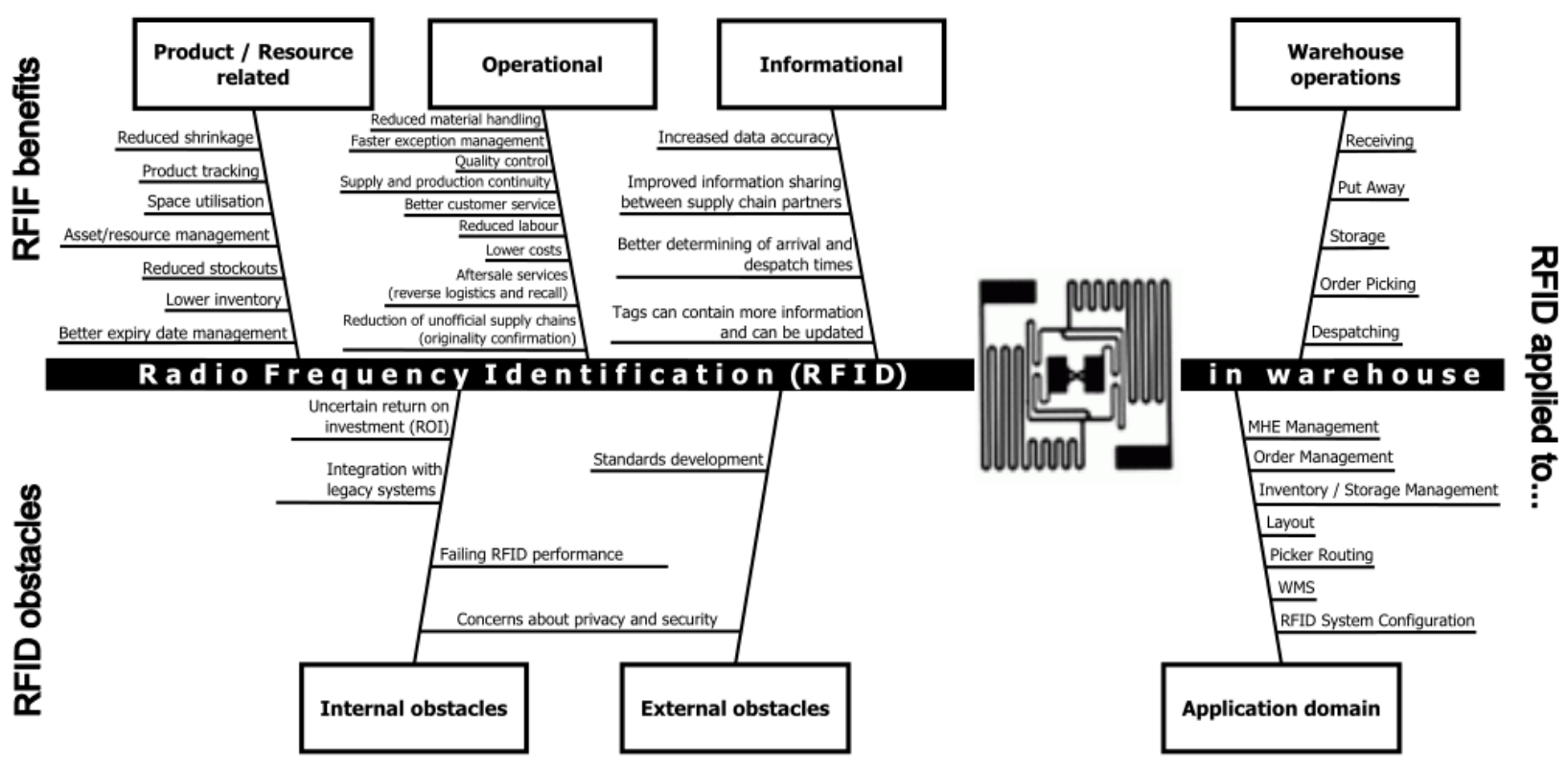

Figure 2. RFID in the warehouse framework 


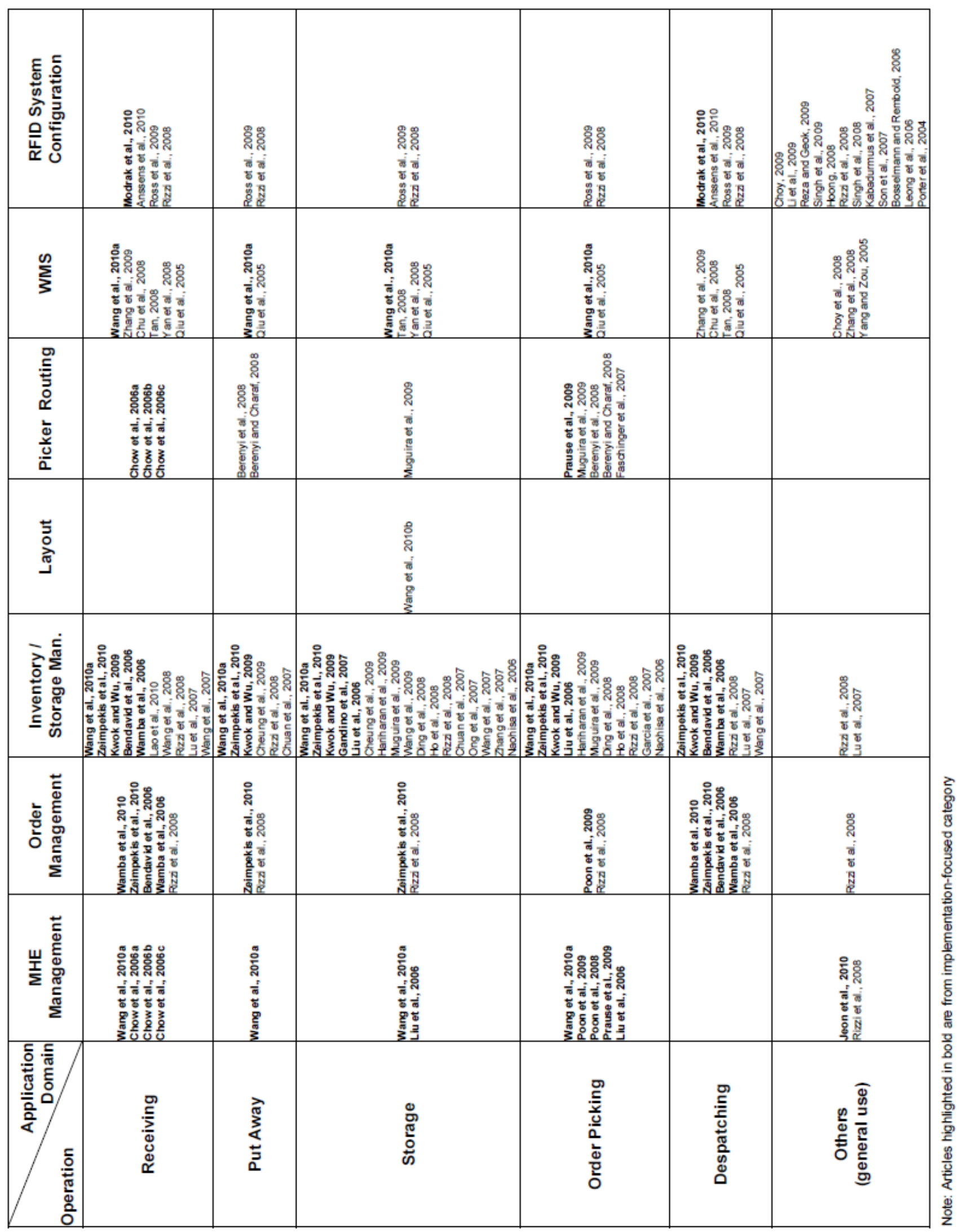

Table 1. Literature category based on application domain and warehouse operation 


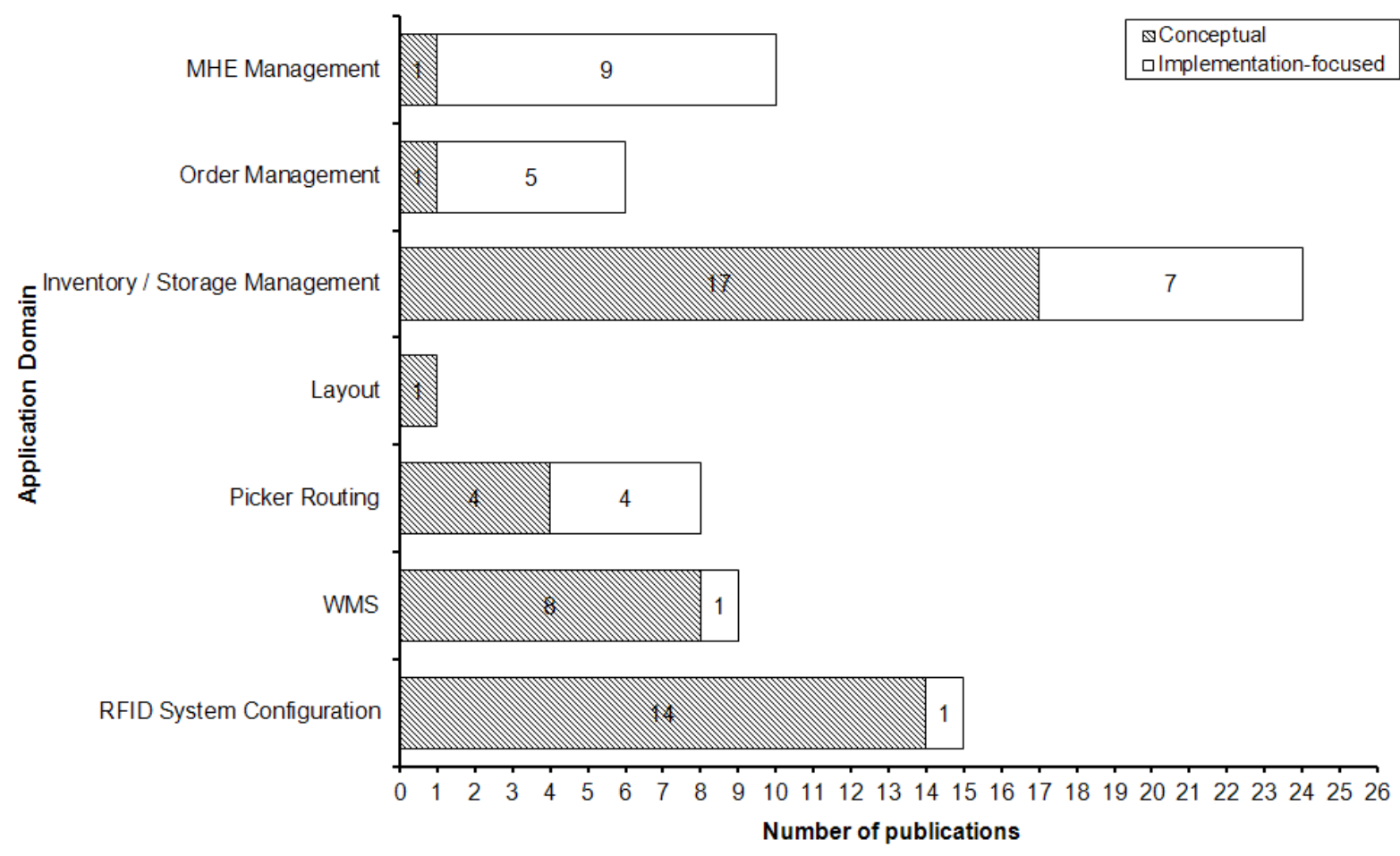

Figure 3. Number of RFID publications in different application domains

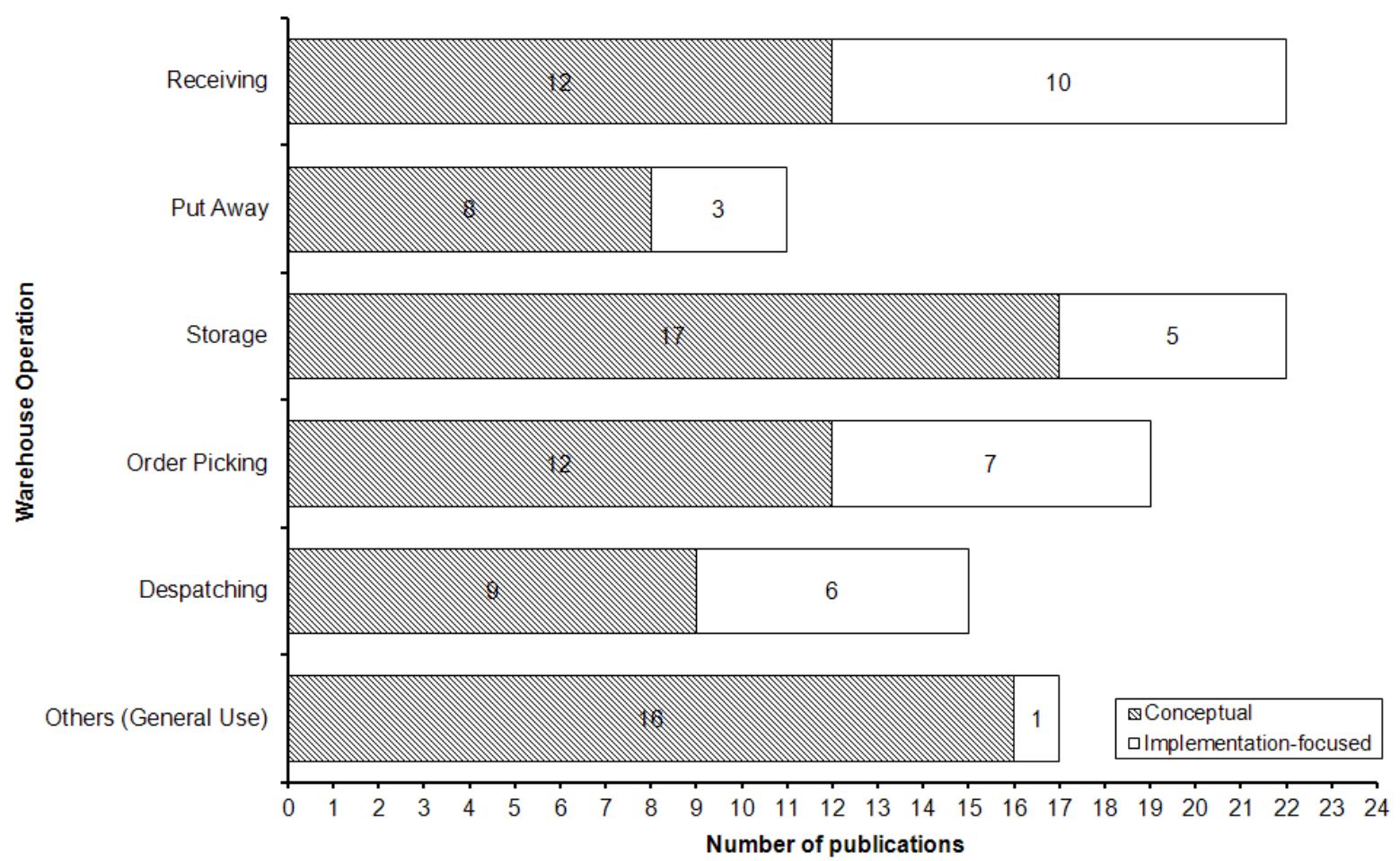

Figure 4. Number of RFID publications in different warehouse operations 


\begin{tabular}{|c|c|c|c|c|c|c|c|c|c|c|}
\hline 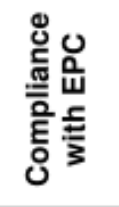 & $\stackrel{\mathscr{D}}{\rightleftharpoons}$ & 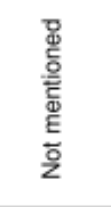 & $\stackrel{\mathscr{\Phi}}{\rightleftharpoons}$ & 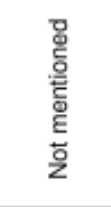 & 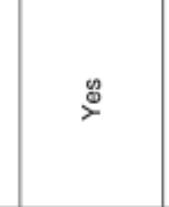 & 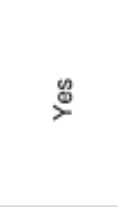 & 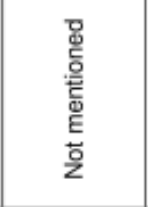 & 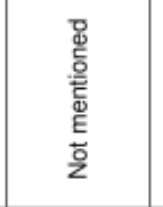 & 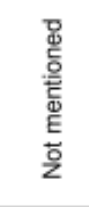 & 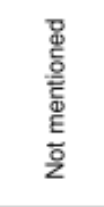 \\
\hline 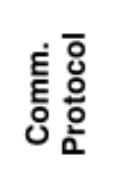 & $\frac{\overline{4}}{3}$ & 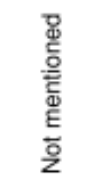 & 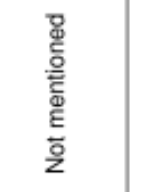 & $\stackrel{\frac{1}{3}}{3}$ & $\stackrel{\frac{15}{3}}{3}$ & 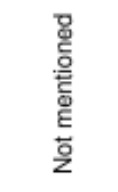 & $z$ & 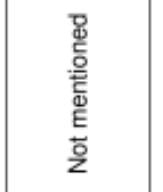 & $z$ & 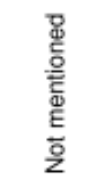 \\
\hline 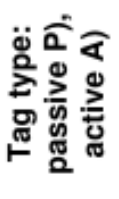 & a & a & a & a & a & a & a. & 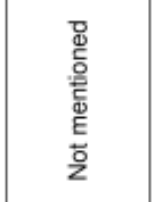 & a & a \\
\hline 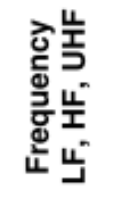 & 泾 & 泾 & 筥 & 㞻 & 堊 & 堊 & $\frac{\underline{\underline{T}}}{\mathrm{~J}}$ & 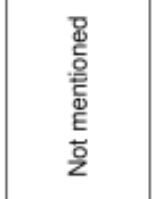 & 荘 & $\begin{array}{l}\text { 㭊 } \\
\text { 竞 }\end{array}$ \\
\hline 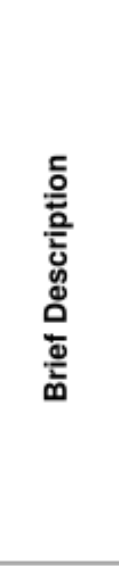 & 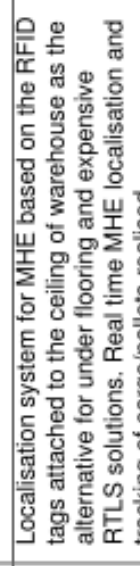 & 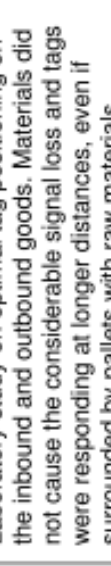 & 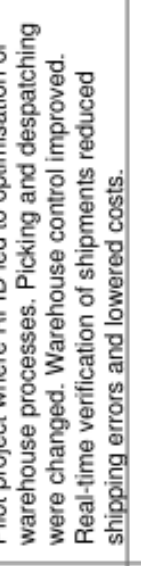 & 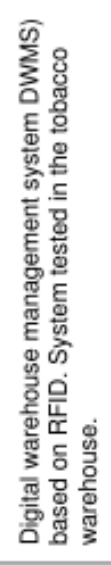 & 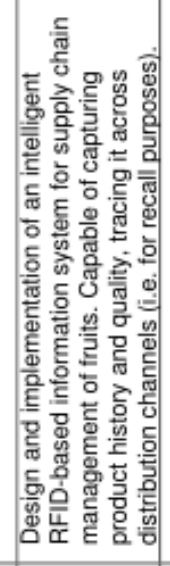 & 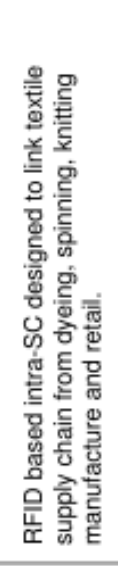 & 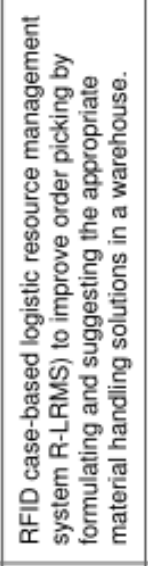 & 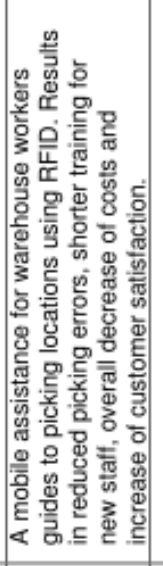 & 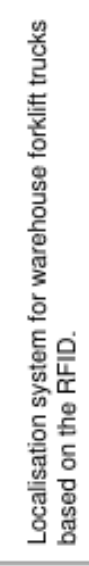 & 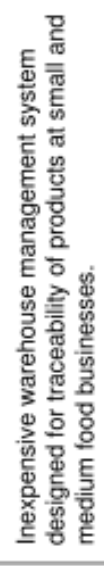 \\
\hline 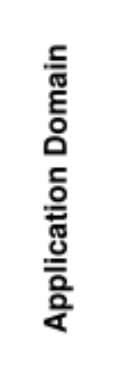 & 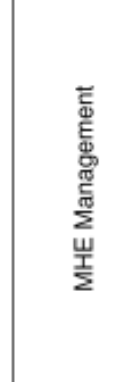 & 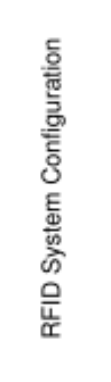 & 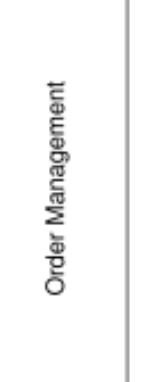 & 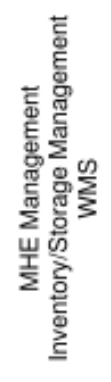 & 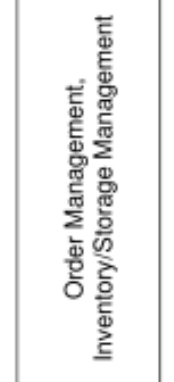 & 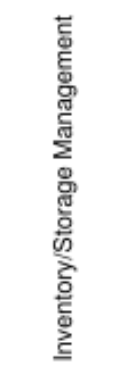 & 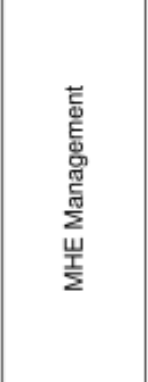 & 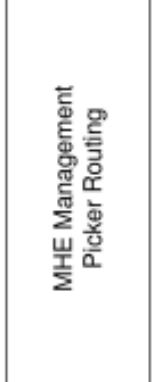 & 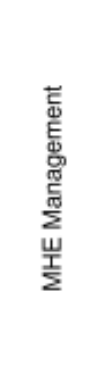 & 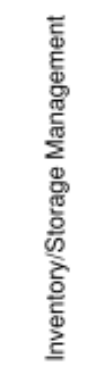 \\
\hline$\frac{\frac{0}{0}}{\frac{t}{4}}$ & 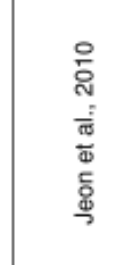 & 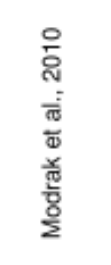 & 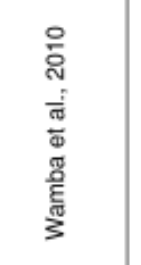 & 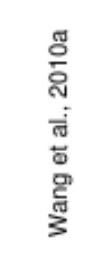 & 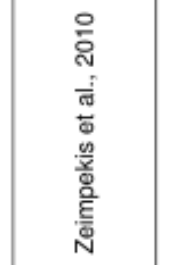 & 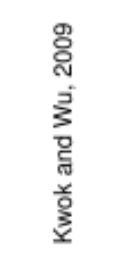 & 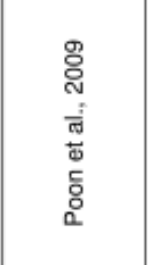 & 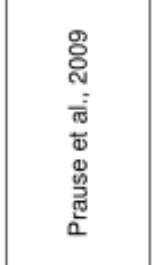 & 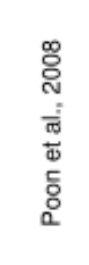 & 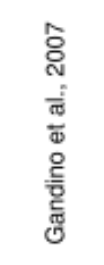 \\
\hline
\end{tabular}

Table 2: Types of RFID system in implementation-focused category 


\begin{tabular}{|c|c|c|c|c|c|c|}
\hline 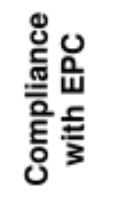 & $\stackrel{\varpi}{\rightleftharpoons}$ & 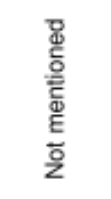 & 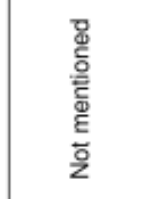 & 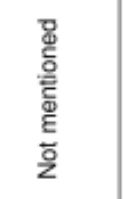 & 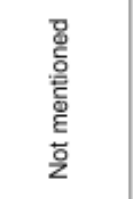 & $\stackrel{\mathscr{g}}{\check{\nu}}$ \\
\hline 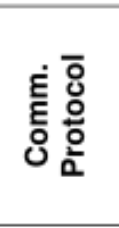 & 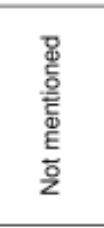 & 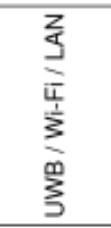 & 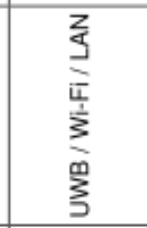 & 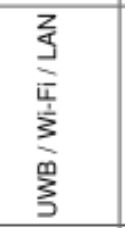 & $\stackrel{\square}{3}$ & 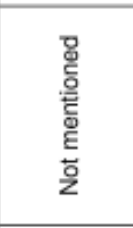 \\
\hline 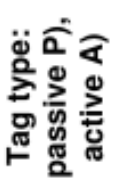 & a & $\underset{a}{a}$ & $\stackrel{a}{a}$ & $a^{4}$ & a & a \\
\hline 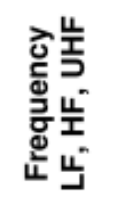 & 㟱 & 㟱 & 㟱 & 坊 & 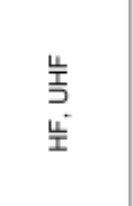 & 崇 \\
\hline 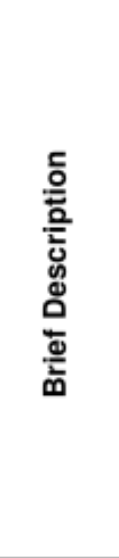 & 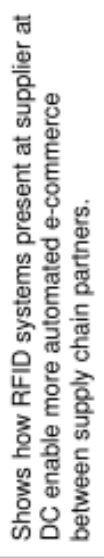 & 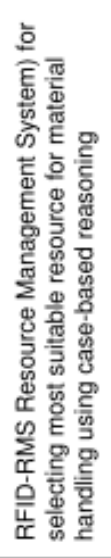 & 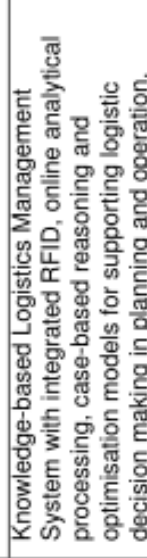 & 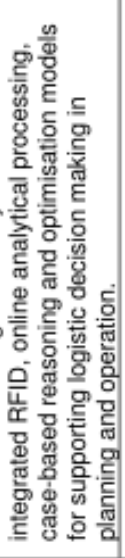 & 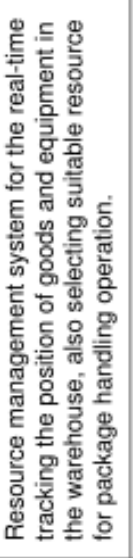 & 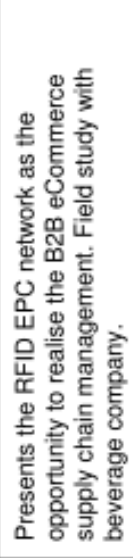 \\
\hline 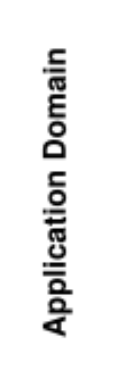 & 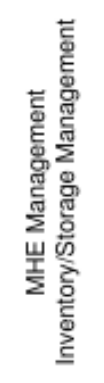 & 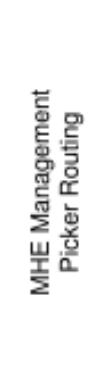 & 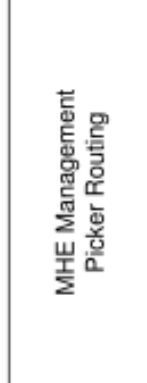 & 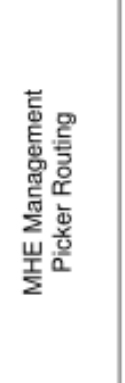 & 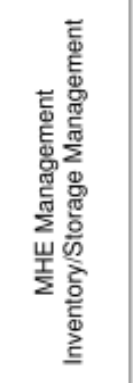 & 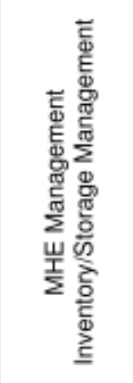 \\
\hline$\frac{\stackrel{0}{0}}{\frac{10}{4}}$ & 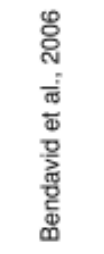 & 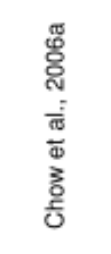 & 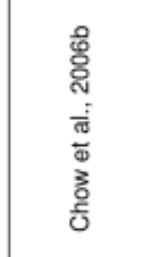 & 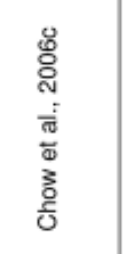 & 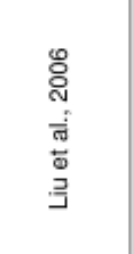 & 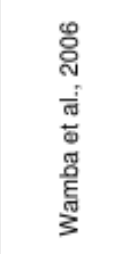 \\
\hline
\end{tabular}

Table 2: Types of RFID system in implementation-focused category (cont.) 


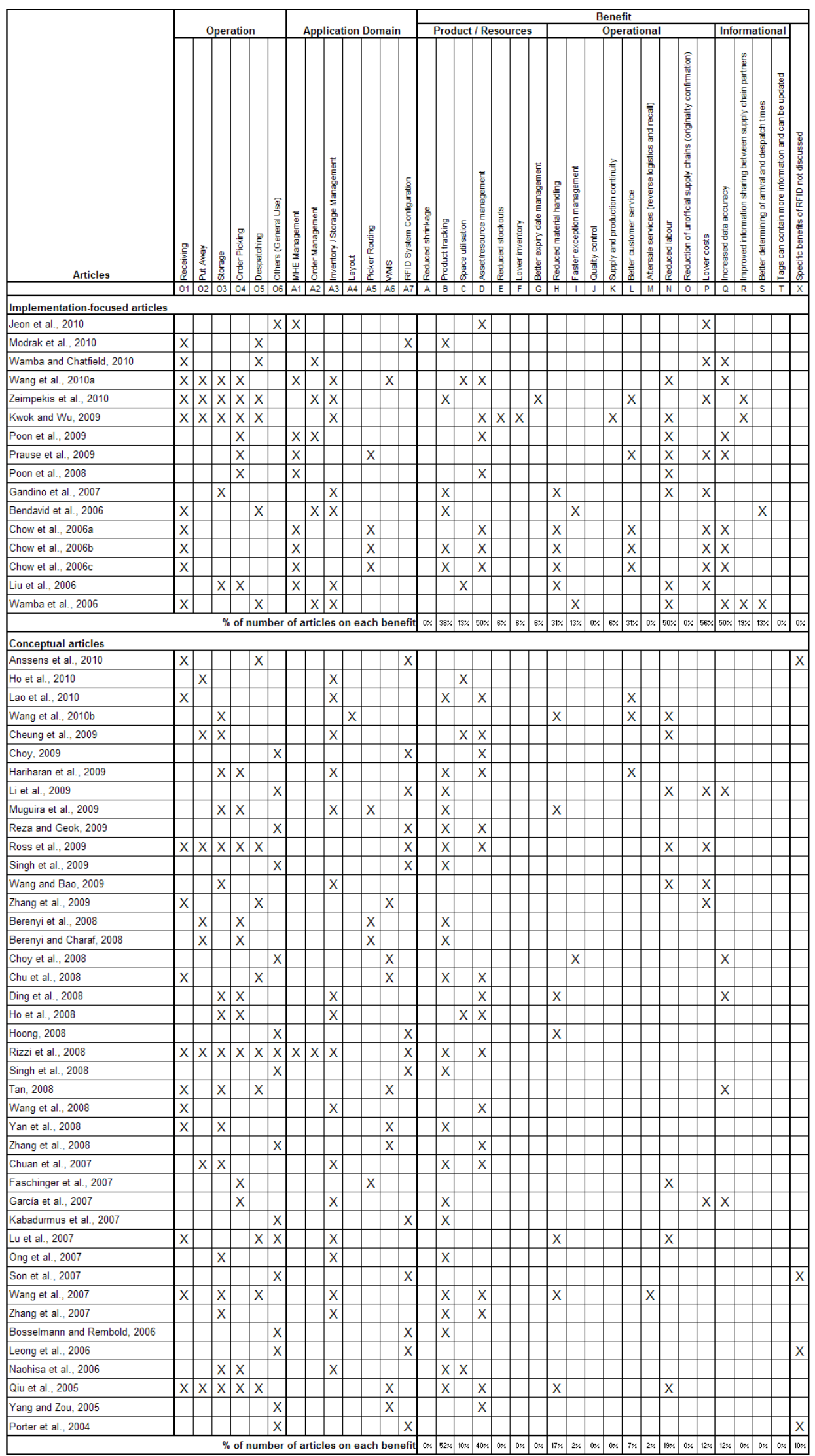

Table 3. RFID benefits based on application domain and warehouse operation. 


\begin{tabular}{|c|c|c|c|c|c|c|c|c|}
\hline & & \multicolumn{6}{|c|}{ Operation } & \multirow{3}{*}{ 要 } \\
\hline & & 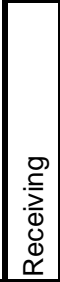 & 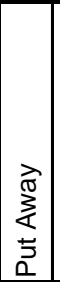 & \begin{tabular}{|l|} 
\\
\\
$\Phi$ \\
$\mathscr{J}$ \\
$\frac{\pi}{0}$ \\
ஸे \\
\end{tabular} & 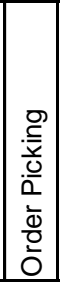 & 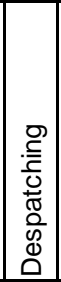 & 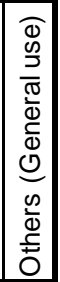 & \\
\hline \multicolumn{2}{|r|}{ Benefit } & 01 & $\mathrm{O} 2$ & $\mathrm{O} 3$ & 04 & 05 & 06 & \\
\hline$B$ & Product tracking & 12 & 7 & 13 & 10 & 8 & 7 & 57 \\
\hline $\mathrm{D}$ & Asset/resource management & 12 & 7 & 12 & 10 & 6 & 6 & 53 \\
\hline $\mathrm{N}$ & Reduced labour & 6 & 5 & 9 & 9 & 5 & 2 & 36 \\
\hline$P$ & Lower costs & 7 & 2 & 5 & 5 & 4 & 2 & 25 \\
\hline $\mathrm{H}$ & Reduced material handling & 6 & 1 & 7 & 4 & 3 & 2 & 23 \\
\hline$Q$ & Increased data accuracy & 7 & 1 & 3 & 5 & 3 & 2 & 21 \\
\hline C & Space utilisation & 1 & 3 & 5 & 4 & 0 & 0 & 13 \\
\hline $\mathrm{L}$ & Better customer service & 5 & 1 & 3 & 3 & 1 & 0 & 13 \\
\hline $\mathrm{R}$ & Improved information sharing between supply chain partners & 3 & 2 & 2 & 2 & 3 & 0 & 12 \\
\hline I & Faster exception management & 2 & 0 & 0 & 0 & 2 & 1 & 5 \\
\hline $\mathrm{K}$ & Supply and production continuity & 1 & 1 & 1 & 1 & 1 & 0 & 5 \\
\hline $\mathrm{E}$ & Reduced stockouts & 1 & 1 & 1 & 1 & 1 & 0 & 5 \\
\hline $\mathrm{F}$ & Lower inventory & 1 & 1 & 1 & 1 & 1 & 0 & 5 \\
\hline $\mathrm{G}$ & Better expiry date management & 1 & 1 & 1 & 1 & 1 & 0 & 5 \\
\hline $\mathrm{X}$ & Specific benefits of RFID not discussed & 1 & 0 & 0 & 0 & 1 & 3 & 5 \\
\hline$S$ & Better determining of arrival and despatch times & 2 & 0 & 0 & 0 & 2 & 0 & 4 \\
\hline $\mathrm{M}$ & Aftersale services (reverse logistics and recall) & 1 & 0 & 1 & 0 & 1 & 0 & 3 \\
\hline A & Reduced shrinkage & 0 & 0 & 0 & 0 & 0 & 0 & 0 \\
\hline $\mathrm{J}$ & Quality control & 0 & 0 & 0 & 0 & 0 & 0 & 0 \\
\hline $\mathrm{O}$ & Reduction of unofficial supply chains (originality confirmation) & 0 & 0 & 0 & 0 & 0 & 0 & 0 \\
\hline \multirow[t]{2}{*}{$\mathrm{T}$} & Tags can contain more information and can be updated & 0 & 0 & 0 & 0 & 0 & 0 & 0 \\
\hline & Tota & 69 & 33 & 64 & 56 & 43 & 25 & \\
\hline
\end{tabular}

Table 4. RFID benefits by the number of publications categorised by warehouse operations. 


\begin{tabular}{|c|c|c|c|c|c|c|c|c|c|}
\hline & & \multicolumn{7}{|c|}{ Application Domain } & \multirow[b]{2}{*}{ 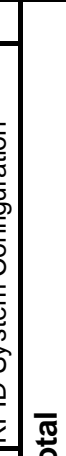 } \\
\hline & & 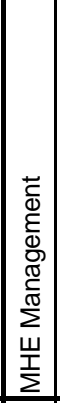 & 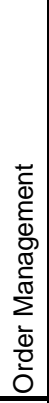 & 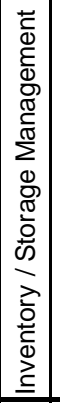 & 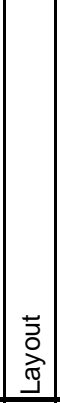 & 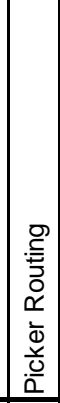 & 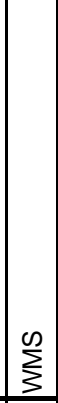 & 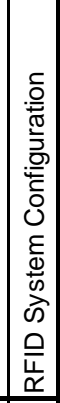 & \\
\hline \multicolumn{2}{|r|}{ Benefit } & A1 & A2 & A3 & A4 & A5 & A6 & A7 & 은 \\
\hline $\mathrm{B}$ & Product tracking & 3 & 3 & 13 & 0 & 5 & 3 & 9 & 36 \\
\hline $\mathrm{D}$ & Asset/resource management & 8 & 2 & 12 & 0 & 3 & 5 & 4 & 34 \\
\hline $\mathrm{N}$ & Reduced labour & 5 & 2 & 8 & 1 & 2 & 2 & 2 & 22 \\
\hline Q & Increased data accuracy & 6 & 3 & 4 & 0 & 4 & 3 & 1 & 21 \\
\hline $\mathrm{P}$ & Lower costs & 6 & 2 & 5 & 0 & 4 & 1 & 2 & 20 \\
\hline $\mathrm{H}$ & Reduced material handling & 4 & 0 & 6 & 1 & 4 & 1 & 1 & 17 \\
\hline $\mathrm{L}$ & Better customer service & 4 & 1 & 3 & 1 & 4 & 0 & 0 & 13 \\
\hline $\mathrm{C}$ & Space utilisation & 2 & 0 & 6 & 0 & 0 & 1 & 0 & 9 \\
\hline $\mathrm{I}$ & Faster exception management & 0 & 2 & 2 & 0 & 0 & 1 & 0 & 5 \\
\hline $\mathrm{R}$ & Improved information sharing between supply chain partners & 0 & 2 & 3 & 0 & 0 & 0 & 0 & 5 \\
\hline $\mathrm{S}$ & Better determining of arrival and despatch times & 0 & 2 & 2 & 0 & 0 & 0 & 0 & 4 \\
\hline $\mathrm{X}$ & Specific benefits of RFID not discussed & 0 & 0 & 0 & 0 & 0 & 0 & 4 & 4 \\
\hline $\mathrm{G}$ & Better expiry date management & 0 & 1 & 1 & 0 & 0 & 0 & 0 & 2 \\
\hline $\mathrm{K}$ & Supply and production continuity & 0 & 0 & 1 & 0 & 0 & 0 & 0 & 1 \\
\hline $\mathrm{E}$ & Reduced stockouts & 0 & 0 & 1 & 0 & 0 & 0 & 0 & 1 \\
\hline $\mathrm{M}$ & Aftersale services (reverse logistics and recall) & 0 & 0 & 1 & 0 & 0 & 0 & 0 & 1 \\
\hline $\mathrm{F}$ & Lower inventory & 0 & 0 & 1 & 0 & 0 & 0 & 0 & 1 \\
\hline A & Reduced shrinkage & 0 & 0 & 0 & 0 & 0 & 0 & 0 & 0 \\
\hline $\mathrm{J}$ & Quality control & 0 & 0 & 0 & 0 & 0 & 0 & 0 & 0 \\
\hline $\mathrm{O}$ & Reduction of unofficial supply chains (originality confirmation) & 0 & 0 & 0 & 0 & 0 & 0 & 0 & 0 \\
\hline \multirow[t]{2}{*}{$\mathrm{T}$} & Tags can contain more information and can be updated & 0 & 0 & 0 & 0 & 0 & 0 & 0 & 0 \\
\hline & 10 & 38 & 20 & 69 & 3 & 26 & 17 & 23 & \\
\hline
\end{tabular}

Table 5. RFID benefits by the number of publications categorised by application domains. 